\title{
A Study on Fluid Self-Excited Flutter and Forced Response of Turbomachinery Rotor Blade
}

\author{
Chih-Neng Hsu \\ Department of Refrigeration, Air Conditioning and Energy Engineering, National Chin-Yi University of Technology, \\ Taichung City 41170, Taiwan
}

Correspondence should be addressed to Chih-Neng Hsu; cnhsu@ncut.edu.tw

Received 29 January 2014; Accepted 4 April 2014; Published 29 May 2014

Academic Editor: Her-Terng Yau

Copyright (C) 2014 Chih-Neng Hsu. This is an open access article distributed under the Creative Commons Attribution License, which permits unrestricted use, distribution, and reproduction in any medium, provided the original work is properly cited.

Complex mode and single mode approach analyses are individually developed to predict blade flutter and forced response. These analyses provide a system approach for predicting potential aeroelastic problems of blades. The flow field properties of a blade are analyzed as aero input and combined with a finite element model to calculate the unsteady aero damping of the blade surface. Forcing function generators, including inlet and distortions, are provided to calculate the forced response of turbomachinery blading. The structural dynamic characteristics are obtained based on the blade mode shape obtained by using the finite element model. These approaches can provide turbine engine manufacturers, cogenerators, gas turbine generators, microturbine generators, and engine manufacturers with an analysis system to remedy existing flutter and forced response methods. The findings of this study can be widely applied to fans, compressors, energy turbine power plants, electricity, and cost saving analyses.

\section{Introduction}

The turbomachinery blade design has been extensively adopted in turbine engines, turbogenerators, microturbine generators, and cogenerators of fans, compressors, and turbine blades. However, excessive vibration due to flutters or forced responses often causes turbomachinery blade failure. Thus, engine manufacturers aim to prevent turbomachinery blade failures to achieve decreased development time and cost, lower maintenance cost, and fewer operational restrictions. One method of preventing blade failures is to increase blade structural damping by using either tip- or midspan shrouded blade designs.

Endurance is one of the most important considerations in turbomachinery blade design. Avoiding responsive blade resonance and preventing instability in turbomachinery are essential to the successful development and operation of gas turbine engines. Vibratory conditions produce stresses, which exceed allowable fatigue strength, reduce engine life, and in some cases even result in failure. Prior assessment of these responses followed by corresponding corrective actions ensures cost-effective designs and development effort.
Forced response is caused by vibration at levels that exceed material endurance limits, thereby causing high cycle fatigue failure. Blades vibrate in normal modes. Hence, a blade may have as many critical or maximum stress points as it has natural modes. The blade designer must determine the normal blade modes and calculate which mode has the greatest potential for resonance excitation. The source of stimuli is normally distorted in the flow to the rotor, which is caused by wakes shed by upstream struts or vanes and by separation of the upstream flow from the inlet. Separation of the upstream flow is normally precipitated by aircraft maneuver, gusts, cross wind, and, on occasion, ingestion of munitions exhaust gases.

\section{Review of Related Literature}

Chiang and Kielb [1] presented a useful design tool to predict potential forced response, over and above the standard Campbell diagram approach. A fan inlet distortion is analyzed with measured distortion, and the predicted response agreed with the measured response. Chiang and Turner [2] developed an analysis system to predict the forced response 
of the compressor rotor blade caused by downstream stator vanes and struts. The description of the potential disturbance flow defect is obtained from a CFD model. The finite element method is used to provide the mode shapes and frequencies for the blade motion. Once structural damping is determined, the blade forced response is predicted by the system.

Murthy and Stefko [3] used the forced response prediction system, a software system, which integrates structural dynamic and steady and unsteady aerodynamic analyses to efficiently predict the forced dynamic stresses of turbomachinery blades to aerodynamic and mechanical excitations. The program also performs flutter analysis. Kielb and Chiang [4] described and assessed the current state of technology, providing examples of current research directions and defining research needs for flow defects, unsteady blade loads, and blade response in forced response analysis of the turbomachinery blade. Izsak and Chiang [5] presented prediction of wake strength as a key element in turbine and compressor forced response analysis. An empirical wake model and a 3D CFD flow solver are used and compared with wake data to assess the accuracy of the method. The empirical wake model predictions are compared with wake data obtained from a low-speed turbine, a compressor research facility, and a high-speed turbine facility. Izsak's paper provides a guide for applying empirical and CFD methods to model turbine and compressor wakes for blade forced response.

Manwaring and Wisler [6] developed a comprehensive series of experiments and analyses performed on compressor and turbine blading to evaluate the ability of current engineering/analysis models to predict unsteady aerodynamic loading of modern gas turbine blading. The predictions are experimentally compared, and their abilities are assessed to help guide designers in using these prediction schemes. Manwaring et al. [7] described a portion of an experimental and computational program, which incorporates measurements of all aspects of the forced response of an airfoil row for the first time. The purpose is to extend knowledge about unsteady aerodynamics associated with a low-aspect-ratio transonic fan, where the flow defects are generated by inlet distortions. Willcox et al. [8] utilized a model order reduction technique that yields low-order models of unsteady blade row aerodynamics. The technique is applied to linearized unsteady Euler CFD solutions in such a way that the resulting blade row models can be linked to their surroundings through their boundary conditions. The technique is also applied to a transonic compressor aeroelastic analysis, which captures high-fidelity CFD forced response results better than models that use single-frequency influence coefficients.

Hall and Silkowski $[9,10]$ presented an analysis of the unsteady aerodynamic response of cascade due to incident gusts or blade vibration, where the cascade is part of a multistage fan, compressor, or turbine. Most current unsteady aerodynamic models assume that the cascade is isolated in an infinitely long duct. This assumption, however, neglects the potentially important influence of neighboring blade rows. Manwaring and Fleeter [11] investigated a series of experiments that is performed in an extensively instrumented axial flow research compressor to observe the physics of the fundamental flow of the unsteady aerodynamics of wake, which generated periodic rotor blade row at realistic values of the reduced frequency.

Phibel and di Mare [12] studied a comparison between a CFD and three-control-volume model for labyrinth seal flutter predictions. Peng [13] investigated a running tip clearance effect on tip vortices of induced axial compressor rotor flutter. Vasanthakumar [14] studied the computation of aerodynamic damping for flutter analysis of a transonic fan. Antona et al. [15] studied the effect of structural coupling on the flutter onset of a sector of flow-pressure turbine vanes. Srivastava et al. [16] investigated a non-linear flutter in fan stator vanes with a time-dependent fixity. Li and Wang [17] evaluated the high-order resonance of a blade under wake excitation. Johann et al. [18] investigated the experimental and numerical flutter analysis of the first-stage rotor in a four-stage high-speed compressor. McGee III and Fang [19] studied a reduced-order integrated design synthesis for a three-dimensional tailored vibration response and flutter control of high-bypass shroudless fans. Aotsuka et al. [20] focused on numerical simulation of the transonic fan flutter with a three-dimensional N-S CFD code.

Zemp et al. [21, 22] conducted an experimental investigation of the forced response of impeller blade vibration in a centrifugal compressor with variable inlet guide vanes in two parts: (1) blade damping and (2) forcing function and FSI computations. Zhou et al. [23] studied the forced response prediction for the last stage of the steam turbine blade, subject to low engine order excitation. Hohi et al. [24] investigated the influence of blade properties on the forced response of mistuned bladed disks. Siewert and Stuer [25] conducted forced response analysis of mistuned turbine bladings. Heinz et al. [26] investigated the experimental analysis of a lowpressure model turbine during forced response excitation.

Kharyton et al. [27] presented a simulation of tip timing measurements of the forced response of a cracked bladed disk. Petrov [28] studied the reduction of forced response levels for bladed disks by mistuning. $\mathrm{Gu}$ et al. [29] investigated the forced response of shrouded blades with an intermittent dry friction force. Green [30] presented the forced response of a large civil fan assembly. Dhandapani et al. [31] investigated the forced response and surge behavior of IP core compressors with ICE-damaged rotor blades. Lin et al. [32] simplified the modeling and parameter analysis on whirl flutter of a rotor. Tang et al. [33] conducted vibration and flutter analysis of an aircraft wing by using equivalent plate models. Zhang et al. [34] investigated the application of HHT and flutter margin method for flutter boundary prediction. Rzadkowski [35] presented the flutter of turbine rotor blades in inviscid flow. Smith [36] studied discrete sound generation frequency in axial flow turbomachinery. Lane [37] investigated system mode shapes in the flutter of compressor blade rows. Srinivasan [38] explained the flutter and resonant vibration characteristics of engine blades. Moyroud et al. [39] studied a modal coupling for fluid and structure analysis of turbomachinery flutter for application to a fan stage. Crawley [40] presented the aeroelastic formulation for tuned and mistuned rotors. Hall and Silkowski [41] and Hsu et al. [4246] focused on the influence of neighboring blade rows on 


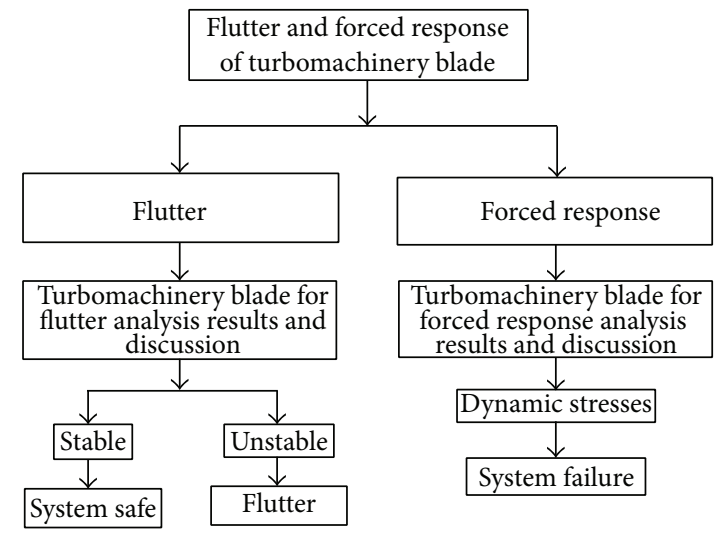

FIGURE 1: Flowchart for the flutter and forced response analysis system.

the unsteady aerodynamics of turbomachinery, flutter, and forced responses.

The unsteady analysis calculates the unsteady forcing functions of inlet distortions to calculate the forced response of turbomachinery blades. Figure 1 shows a flowchart for the flutter and forced response analysis system. This study utilizes the aeroelastic model to simulate three-dimensional aeroelastic effects by calculating the unsteady aerodynamic loads on two-dimensional strips, which are stacked from hub to tip along the span of the blade.

\section{Theoretical and Numerical Analysis}

\subsection{Analysis System}

\subsubsection{Mathematical Model}

Dynamic Equation of Motion. The forced response prediction system is based on an earlier developed system [11], which models the forced response of a blade caused by inlet distortion and upstream wake/shock excitation. The forced response prediction system is applied to incorporate a CFD solver to model downstream or upstream flow defects.

The forced response prediction system starts with the dynamic equations of motion, which is a system of equations for the $n$ degrees of freedom of the system:

$$
[M]\{\ddot{X}\}+[G]\{\dot{X}\}+[K]\{X\}=\left\{F_{m}(t)\right\}+\left\{F_{g}(t)\right\} .
$$

The $[M],[G]$, and $[K]$ matrices represent the inertia, damping, and stiffness properties of the blade, respectively, with $\{X\}$ being the $n$ degree-of-freedom displacement. In this equation, all blades in a blade row are assumed to be vibrating as a tuned rotor, in which all blades have identical frequencies and mode shapes. The forcing terms on the right-hand side of (1) represent the motion-dependent unsteady aerodynamic forces $\left\{F_{m}(t)\right\}$ and the gust response unsteady aerodynamic forces $\left\{F_{g}(t)\right\}$.

The solution of the undamped homogeneous form of (1) results in a set of modal properties, which are the frequencies and mode shapes for $m$ modes. Using these modal properties, the displacements $\{X\}$ can be expressed as

$$
\{X(t)\}=[\varphi]\{Q(t)\},
$$

where $[\varphi]$ is the $n \times m$ mode shape matrix and $\{Q(t)\}$ is the modal displacement.

Substituting (2) with (1) and premultiplying by $[\varphi]^{T}$, the transpose of the modal matrix, results in the modal equation of motion as follows:

$$
\begin{array}{r}
{\left[M_{m}\right]\{\ddot{Q}\}+\left[G_{m}\right]\{\dot{Q}\}+\left[K_{m}\right]\{Q\}} \\
=[\varphi]^{T}\left(\left\{F_{m}(t)\right\}+\left\{F_{g}(t)\right\}\right),
\end{array}
$$

where

$$
\begin{aligned}
& {\left[M_{m}\right]=[\varphi]^{T}[M][\varphi] \text { is the generalized mass matrix, }} \\
& {\left[K_{m}\right]=[\varphi]^{T}[K][\varphi] \text { is the generalized stiffness matrix, }} \\
& {\left[G_{m}\right]=[\varphi]^{T}[G][\varphi] \text { is the generalized damping matrix, }}
\end{aligned}
$$

which, in general, is a full matrix. Here, this damping matrix is assumed to be a diagonal matrix consisting of modal damping coefficients.

With the assumption of simple harmonic motion, the modal displacement $\{Q(t)\}$ can be expressed as

$$
\{Q(t)\}=\{\bar{Q}\} e^{i \omega t} .
$$

The motion-dependent unsteady aerodynamic forces $\left\{F_{m}(t)\right\}$ and the gust response unsteady aerodynamic forces $\left\{F_{g}(t)\right\}$ are expressed as

$$
\begin{gathered}
\left\{F_{m}(t)\right\}=[A]\{\bar{Q}\} e^{i \omega t}, \\
\left\{F_{g}(t)\right\}=\left\{\bar{F}_{g}\right\} e^{i \omega t},
\end{gathered}
$$

where $[A]$ is the unsteady aerodynamic forces due to harmonic motion of the blade and $\left\{\bar{F}_{g}(t)\right\}$ is the unsteady aerodynamic forces acting on the rigid blade due to a sinusoidal gust. 


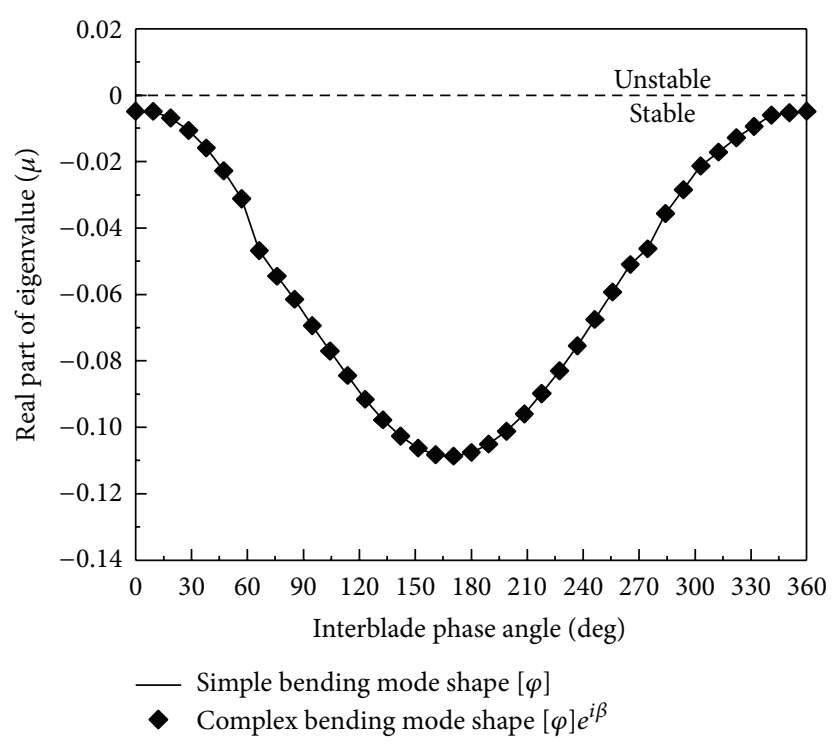

FIgUre 2: Complex mode flutter analysis verification.

Substituting (4) and (5) with (3) and dividing by $e^{i \omega t}$ shows

$$
\begin{aligned}
&-\omega^{2} {\left[M_{m}\right]\{\overline{\mathrm{Q}}\}+i \omega\left[G_{m}\right]\{\overline{\mathrm{Q}}\}+\left[K_{m}\right]\{\overline{\mathrm{Q}}\} } \\
&=[\varphi]^{T}\left([A]\{\overline{\mathrm{Q}}\}+\left\{\bar{F}_{g}\right\}\right),
\end{aligned}
$$

where $[A]$ is obtained by using the motion-dependent unsteady aerodynamic program with input of mode shapes and frequencies provided by a finite element vibratory analysis. $\left\{\bar{F}_{g}\right\}$ is calculated by using the same unsteady aerodynamic program with input from a flow defect model.

3.1.2. Modal Aeroelastic Solution. Structural damping $\left[G_{m}\right]$ is estimated by using previous experience or measured data. The blade modal response is calculated with the unsteady aerodynamic loading $\left\{\bar{F}_{g}\right\}$, the motion-dependent unsteady aerodynamic forces $[A]$, and the structural damping $\left[G_{m}\right]$ as input, as seen in

$$
\{\bar{Q}\}=\left[-\omega^{2}\left[M_{m}\right]+i \omega\left[G_{m}\right]+\left[K_{m}\right]-[\varphi]^{T}[A]\right]^{-1}[\varphi]^{T}\left\{\bar{F}_{g}\right\} .
$$

The blade modal response $\{\bar{Q}\}$ is used to calculate the vibratory blade stress by using the modal stress information.

3.1.3. Model Check. A simple mode shape with only the real mode component is used to check the consistency of the complex mode flutter analysis. Two flutter analyses are performed; one with the real component mode shape $[\varphi]$ and the other with an identical mode shape, but at a different blade location of $[\varphi] e^{i \beta}$, the neighboring blade of $[\varphi]$. This identical mode shape is a complex mode shape with real and imaginary component parts. Using a single mode shape flutter analysis and a complex mode shape flutter analysis should yield the same flutter results because these two are identical mode shapes. Figure 2 shows that the two flutter analyses obtain identical results. Therefore, complex mode shapes can be used with real and imaginary mode components.

\section{Static State Blade Experimental Analysis}

For the experimental testing and analysis, we used the static state blade experimental approach to measure the midspan and tip-shrouded blade response frequency and amplitude magnitude. The static state blade experimental approach uses a spectrum analyzer, a hammer for PCB model, an ICP accelerometer, a notebook/PC, rubber bands, blades, and a setup system, as shown in Figure 3.

(1) Spectrum Analyzer. PHOTON II is used to test static and dynamic signal analyses (e.g., FFT, frequency, amplitude, $\mathrm{rpm}$, waterfall, $\mathrm{dB}$, frequency response function, frequency response spectrum, and coherence function). According to the Nyquist rule, the measurement frequency band can be obtained 2.5 to 3.5 times, and the testing signal can be fully repeated.

(A) Frequency Response Function. The formula for the frequency response function area is $H_{1}(f)=G_{x y}(f) / G_{x x}(f)$, where $G_{x y}$ is the input and output cross frequency and $G_{x x}$ is the power frequency.

(B) Frequency Response Spectrum. The frequency response spectrum is the maximum value of the system frequency and appears as the optimal resonance value. The formula for the frequency response spectrum is $H_{2}(f)=G_{y y}(f) / G_{y x}(f)$, where $G_{y x}$ is the input and output cross frequency and $G_{y y}$ is the power frequency.

(C) Coherence Function. The formula for the coherence function area is $\gamma^{2}(f)=\left[G_{x y}(f)\right]^{2} /\left(G_{x x}(f) \times G_{y y}(f)\right)=$ $H_{1}(f) / H_{2}(f)$, where $0 \leq \gamma^{2}(f) \leq 1$. This formula can use both the Hanning window and the exponential window. 
Static state setup system

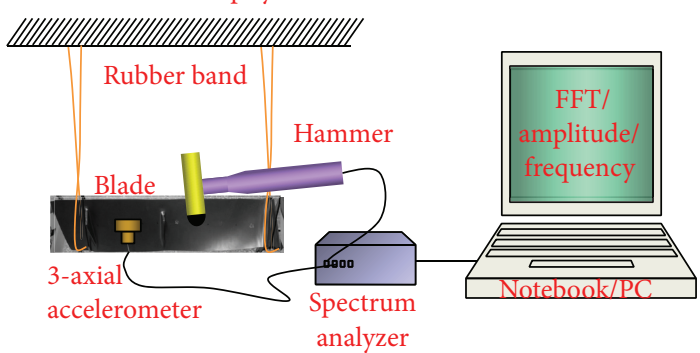

FIGURE 3: Static state testing and setup system.

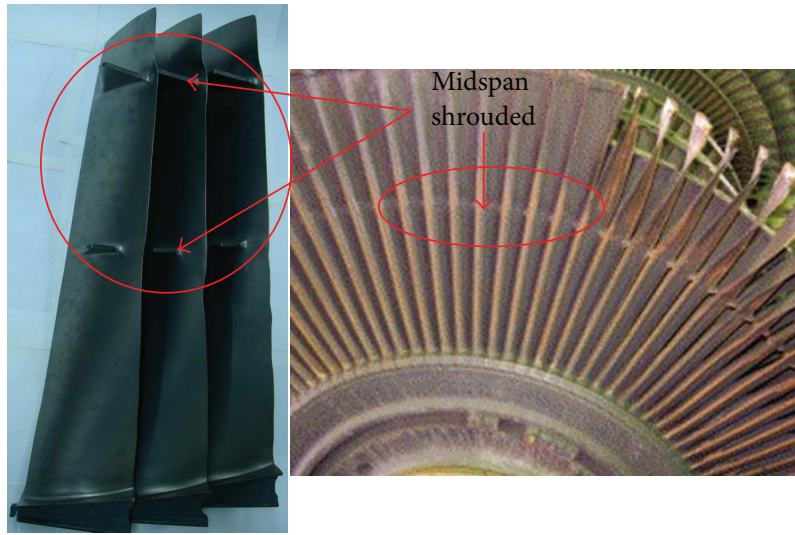

FIgURE 4: Turbomachinery midspan shrouded blade model design.

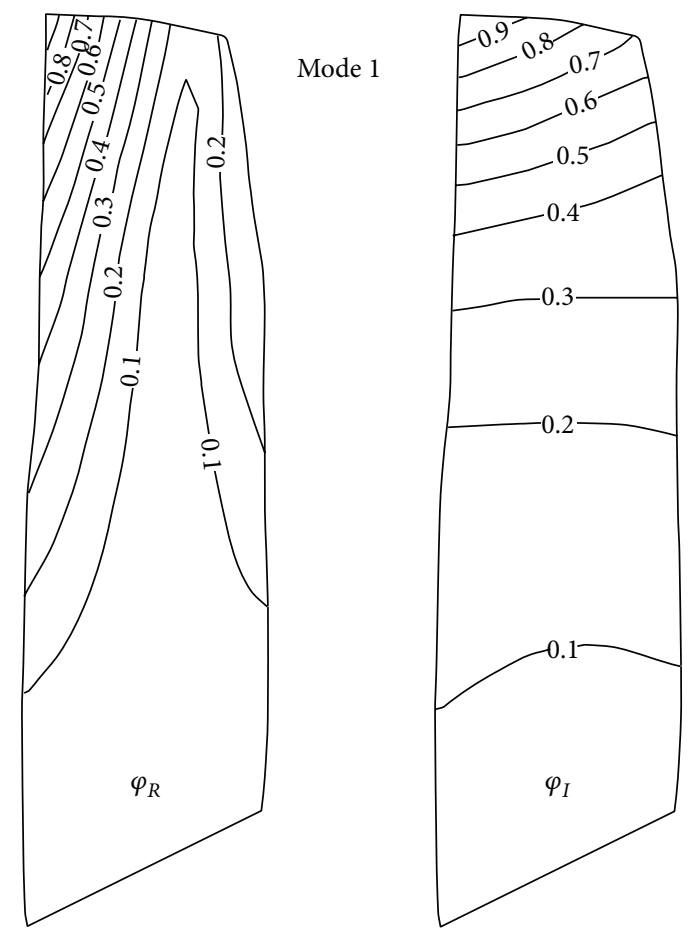

FIGURE 5: First system mode of midspan shrouded blade. 

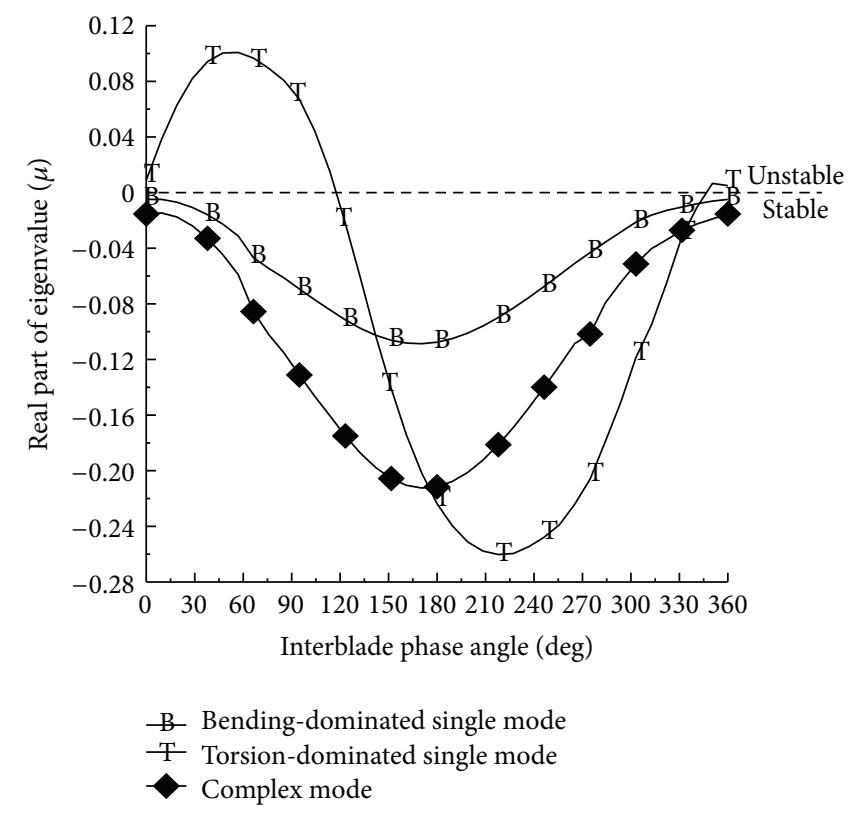

FIGURE 6: First system mode stability of midspan shrouded blade.

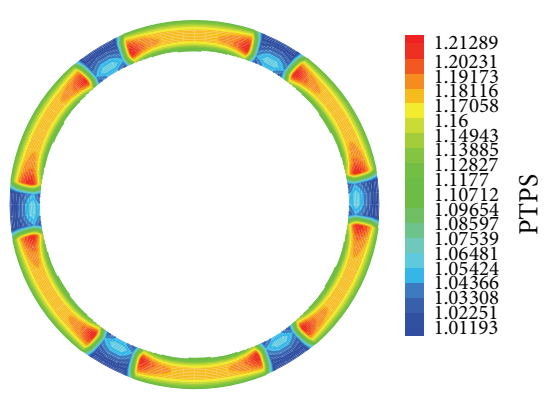

(a) A ratio of span wise interpolated and input and computed PS

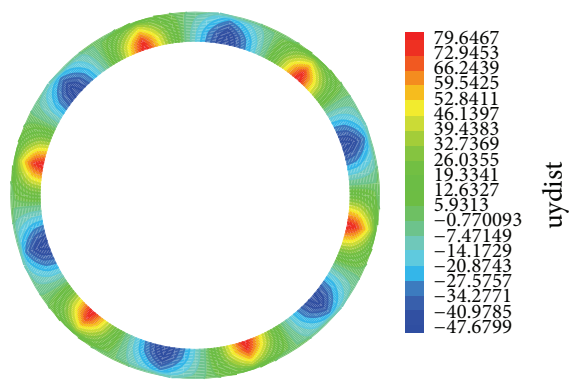

(d) Distorted tangential velocity ( $\mathrm{ft} / \mathrm{sec})$

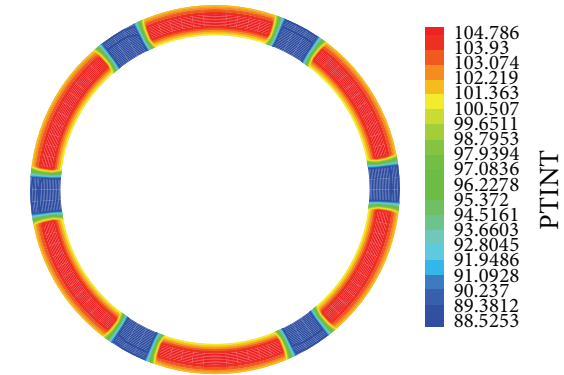

(b) Inlet total pressure (psi)

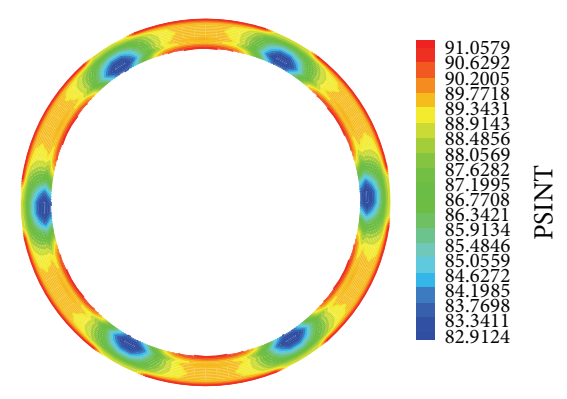

(c) Inlet static pressure (psi)

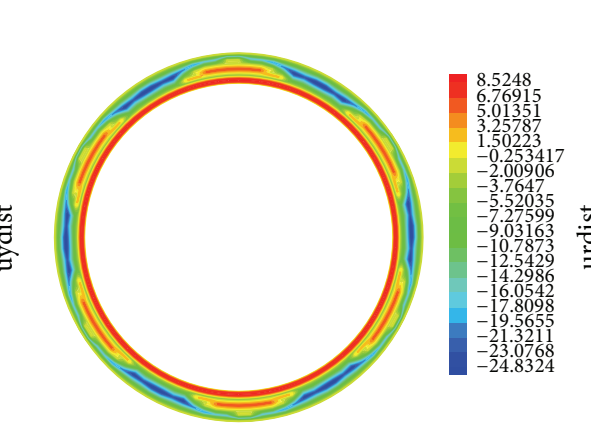

(e) Distorted radial velocity (ft/sec)

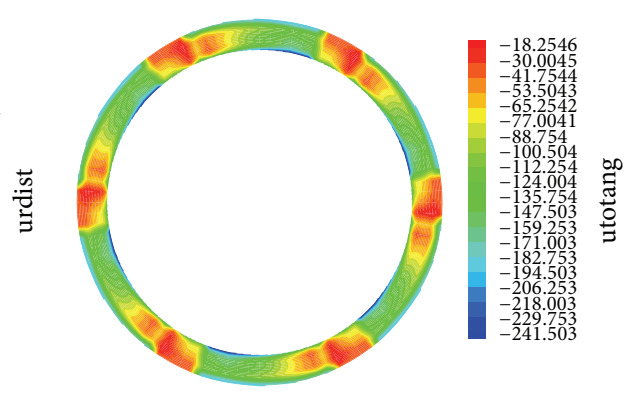

(f) Total tangential velocity (ft/sec)

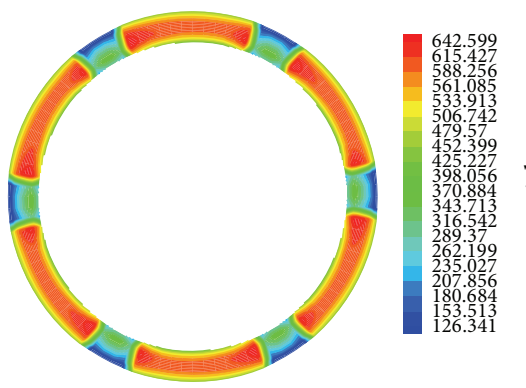

(g) Axial velocity ( $\mathrm{ft} / \mathrm{sec})$

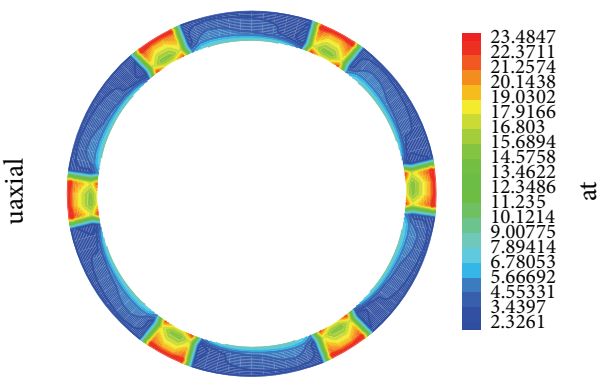

(h) Incidence angle (degree)

FIGURE 7: Forcing function characteristics analysis for six sectors of the midspan shrouded blade. 


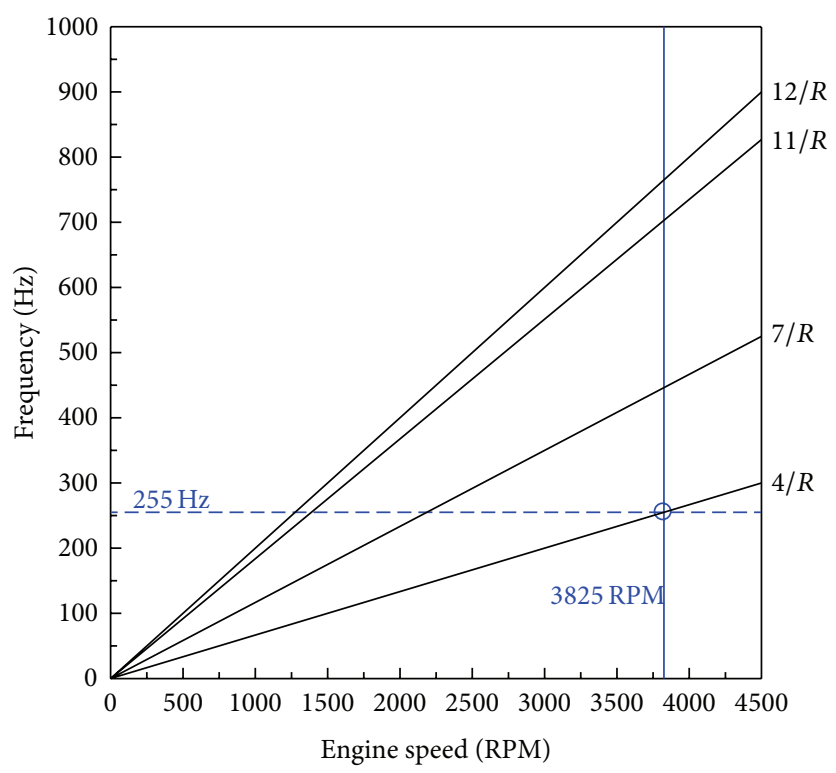

FIgURE 8: Campbell diagram for the midspan shrouded blade.

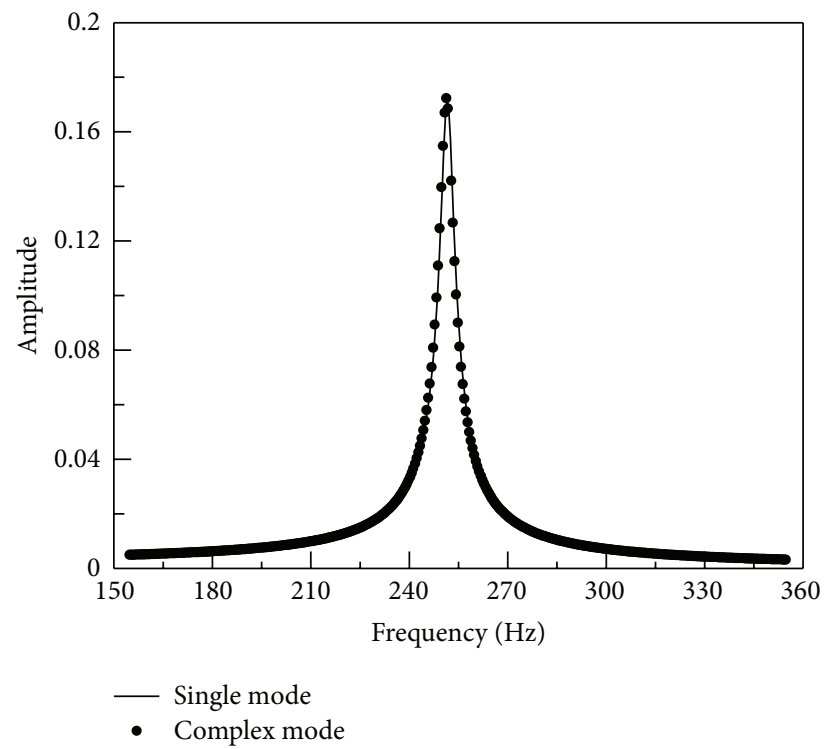

FIGURE 9: Single and complex modes verification for the midspan shrouded blade.

(2) Triaxial Accelerometer (ICP number 356B21). Specifications for the triaxial accelerometer are as follows. Accelerometer sensitivity is $1.02 \mathrm{mV} /\left(\mathrm{m} / \mathrm{s}^{2}\right)(10 \mathrm{mV} / \mathrm{gn})$; measurement range is $\pm 4905 \mathrm{~m} / \mathrm{s}^{2} \mathrm{pk}$; frequency range is $2 \mathrm{~Hz}$ to $10000 \mathrm{~Hz}$ ( $y$ or $z$ axis, $\pm 5 \%$ ) and $2 \mathrm{~Hz}$ to $7000 \mathrm{~Hz}$ ( $x$ axis, $\pm 5 \%$ ); resonant frequency is $\geqq 55 \mathrm{kHz}$; broadband resolution $(1 \mathrm{~Hz}$ to $10000 \mathrm{~Hz}$ ) is $0.04 \mathrm{~m} / \mathrm{s}^{2} \mathrm{rms}$; overload limit (shock) is $\pm 98100 \mathrm{~m} / \mathrm{s}^{2} \mathrm{pk}$; temperature range is (operating) $-54^{\circ} \mathrm{C}$ to $+121^{\circ} \mathrm{C}$; excitation voltage is $18 \mathrm{VD}$ to $30 \mathrm{VD}$; size is $10.2 \mathrm{~mm} \times$ $10.2 \mathrm{~mm} \times 10.2 \mathrm{~mm}$; weight is $4 \mathrm{~g}$; electrical connector is 8 to
36 4-pin; housing material is Ti; sensing element is ceramic; sensing geometry is shear.

(3) Hammer for PCB Model. The hammer for PCB model is used to knock the blade at different points to understand the impulse excitation material of the static state structure of the rotor blade and the natural frequency under the freefree and modal modes. The hammer is also used to knock the blade to predict the excitation frequency range of the element material, the vibration modal mode, and the physical behavior. 

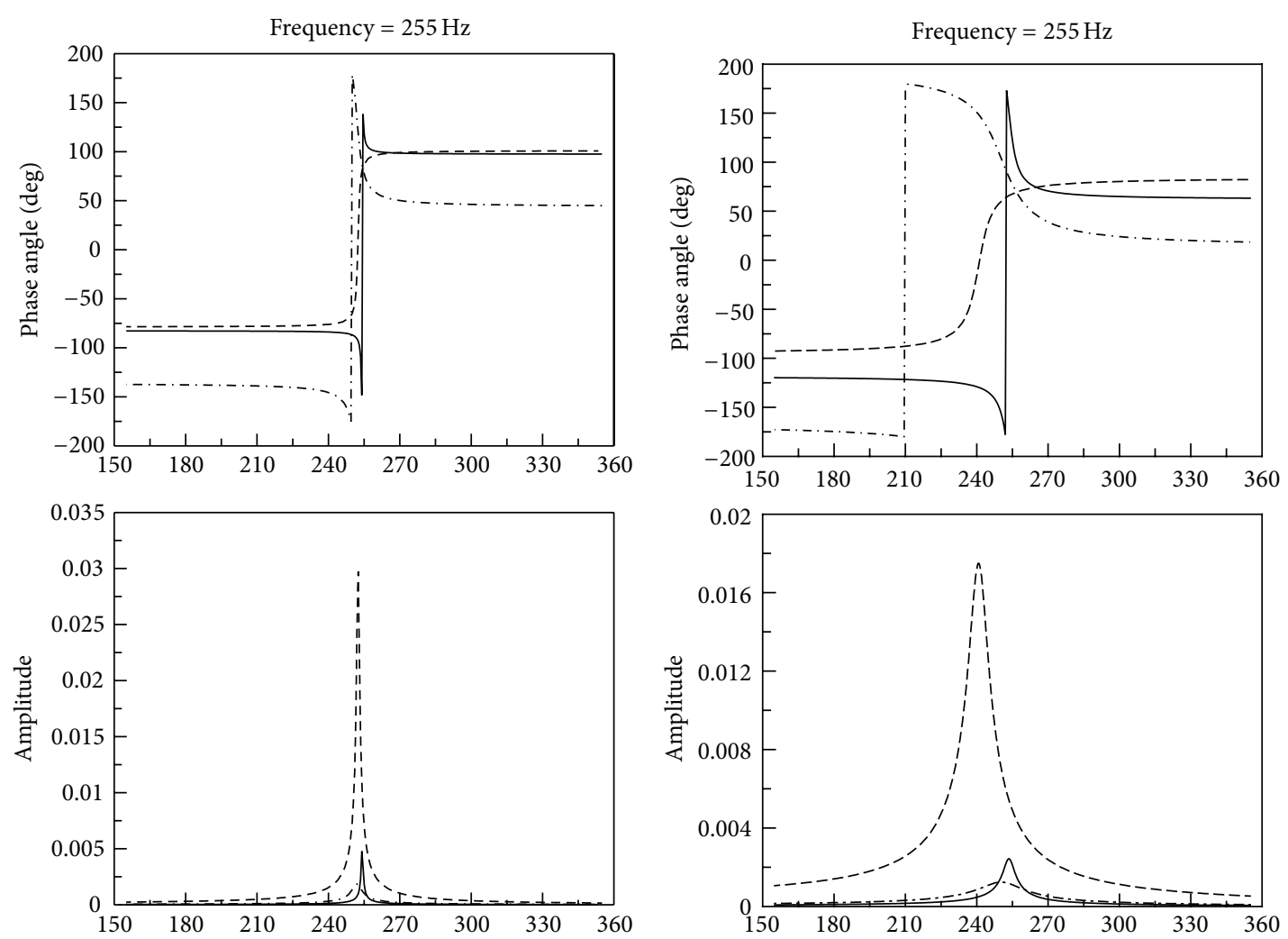

(a) $\mathrm{GA}=0$ degree

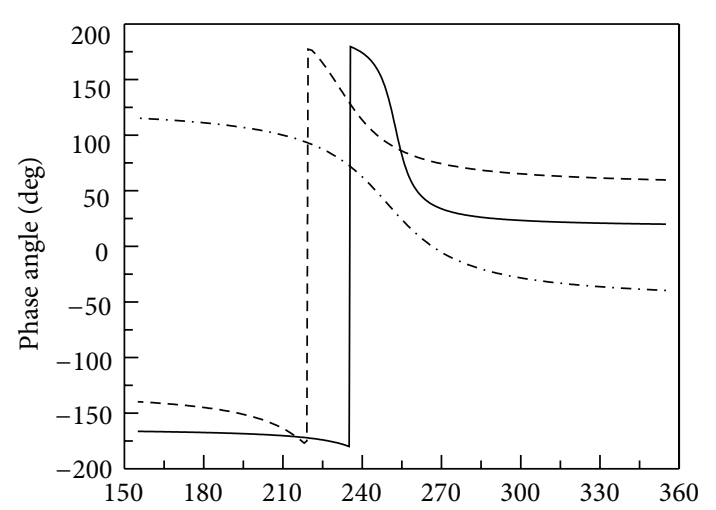

(b) $\mathrm{GA}=60$ degree
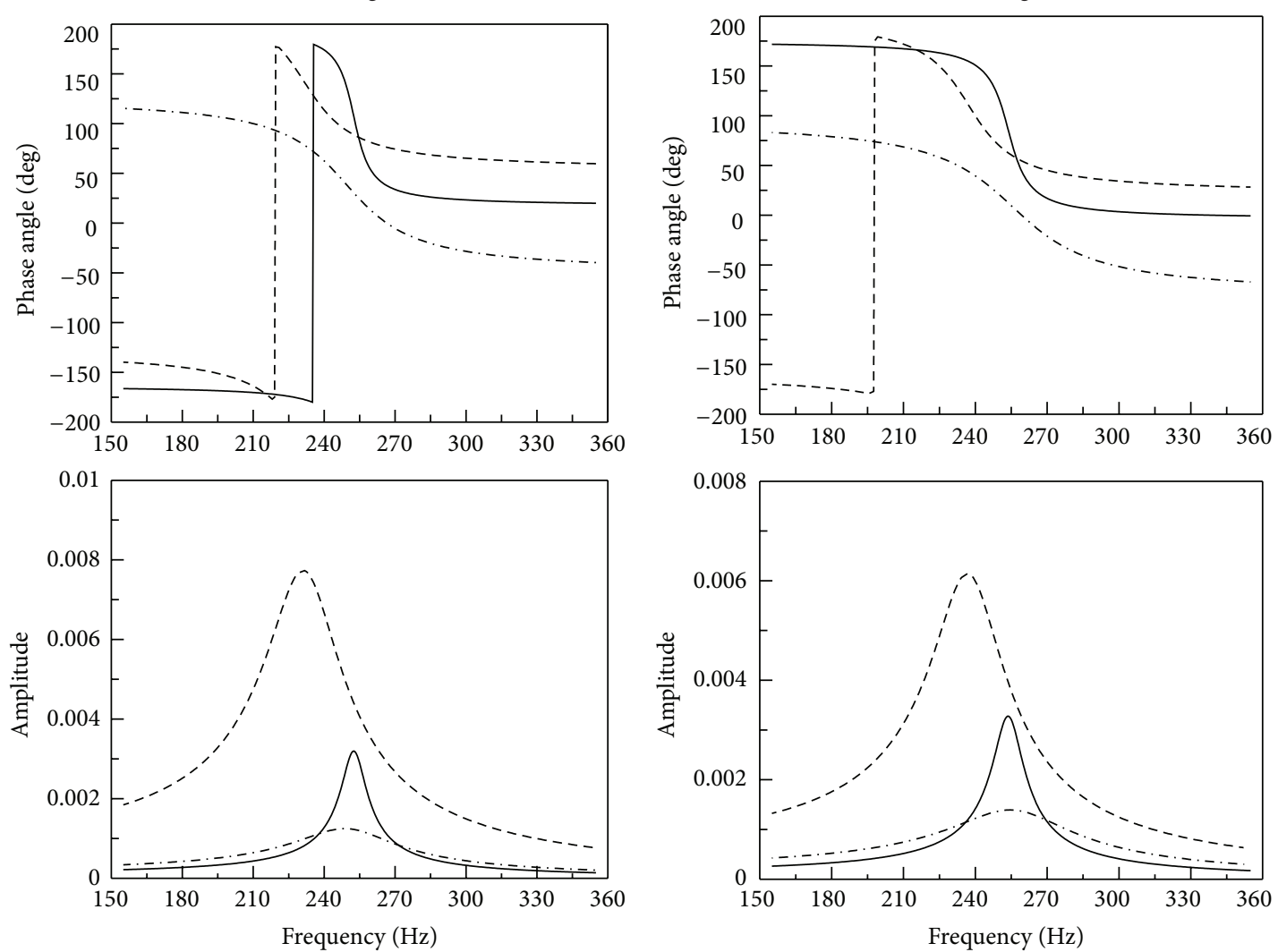

$\begin{array}{ll}\text { _- Bending mode } & \text {-..- Complex mode } \\ \text {-- } & \text { Torsion mode }\end{array}$

(c) $\mathrm{GA}=120$ degree

$\begin{array}{lll}\text { - } & \text { Bending mode } \\ \text {-- } & \text { Torsion mode }\end{array}$

(d) $\mathrm{GA}=180$ degree

FIgURE 10: Continued. 

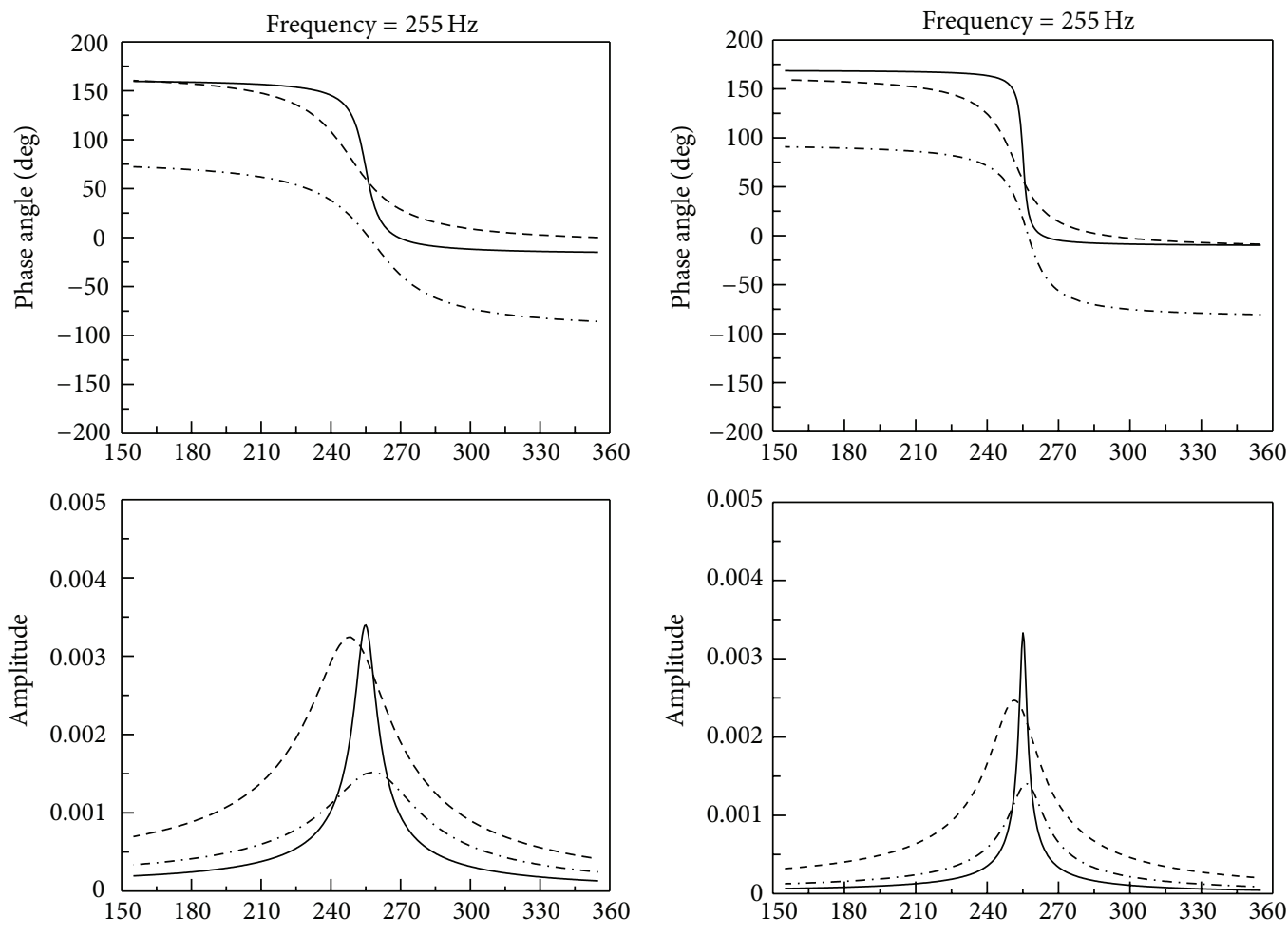

(e) $\mathrm{GA}=240$ degree

(f) $\mathrm{GA}=300$ degree
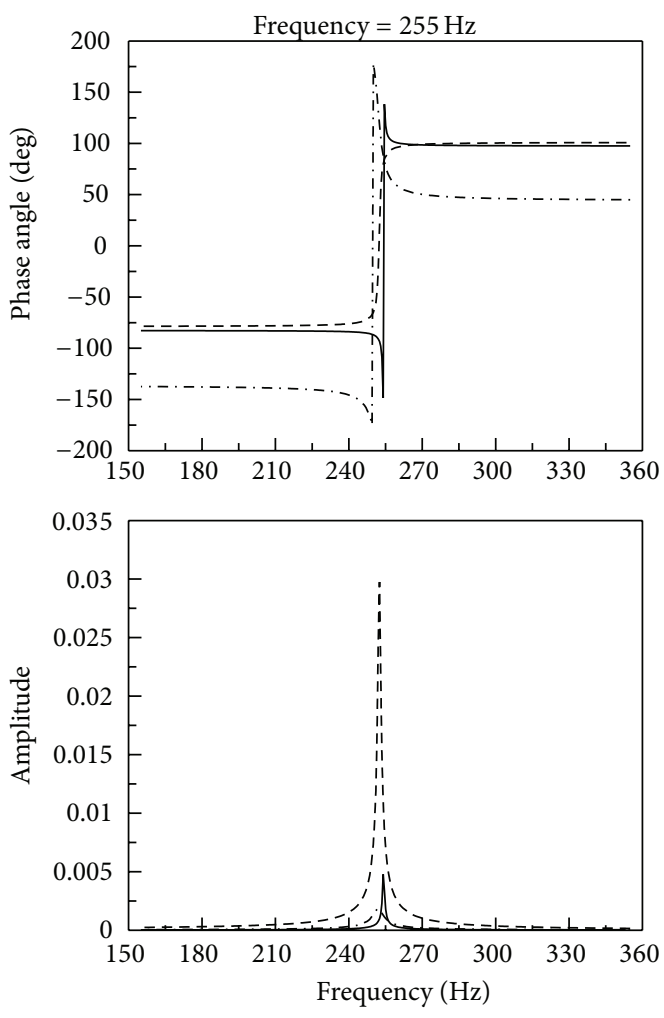

- Bending mode

-.- Complex mode

- - - Torsion mode

(g) $\mathrm{GA}=360$ degree

Figure 10: First system mode $(255 \mathrm{~Hz})$ forced response for interblade phase angles of $0,60,120,180,240,300$, and $360^{\circ}$ of the midspan shrouded blade. 

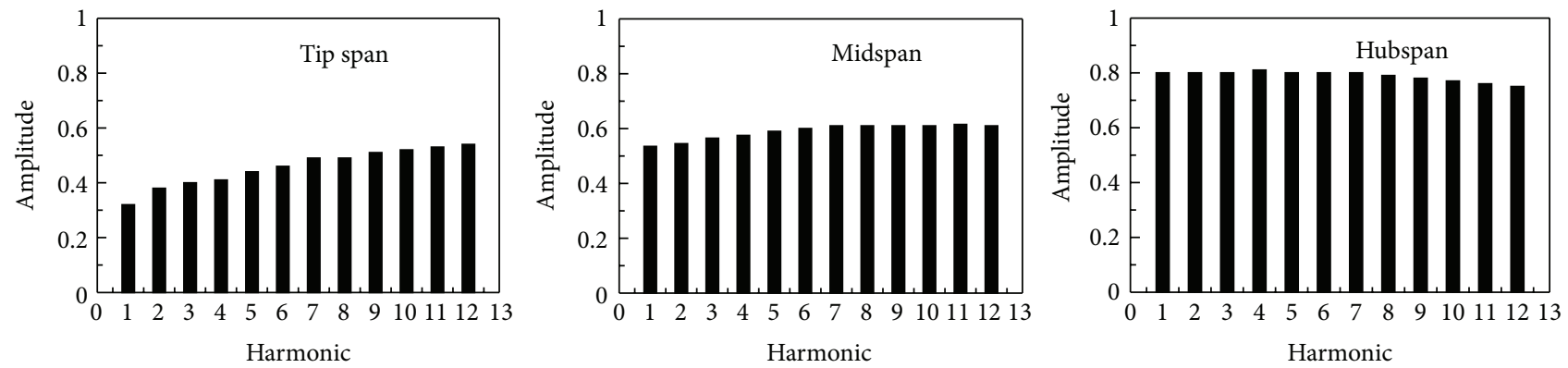

FIGURE 11: Amplitude intensity of the midspan shrouded blade.

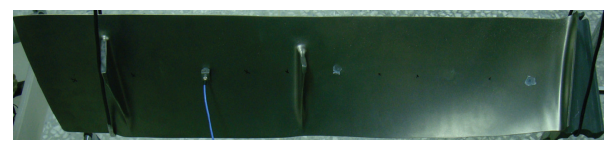

(a) Midspan blade experimental testing

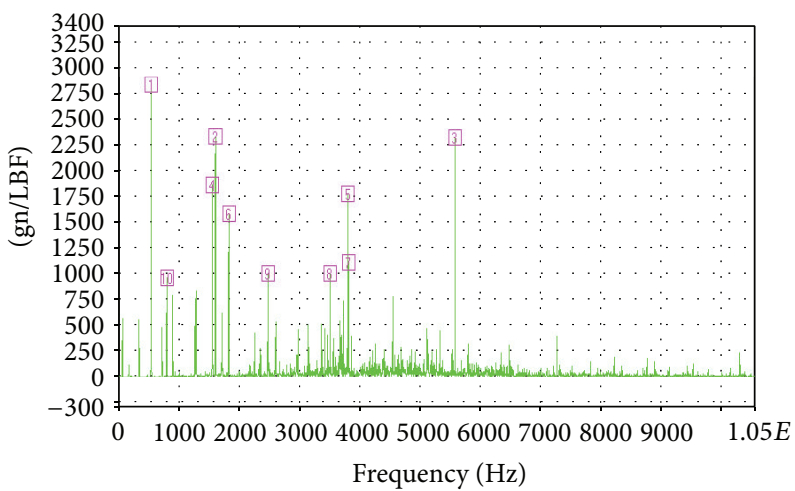

X

(1) $539.1 \quad 2830$

(2) $1603 \quad 2333$

(3) $5569 \quad 2314.48$

(4) $1550 \quad 1863.92$

(5) $3800 \quad 1776.67$

(c) $Y$-directional analysis

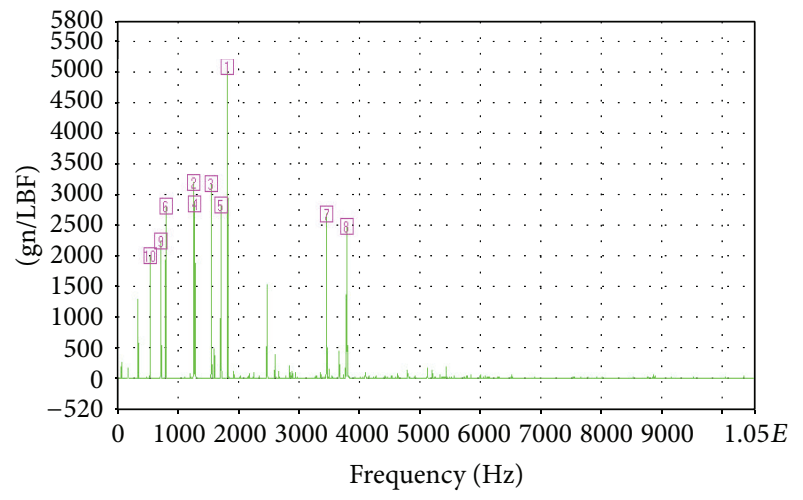

$H 1 \_2,1(f) \quad$ X $\quad Y$
(1) $1822 \quad 5069.01$
(6) $796.9 \quad 2810.42$
(2) $1263 \quad 3191.39$
(3) $1550 \quad 3161.37$
(4) $1277 \quad 2831.57$
(5) $1711 \quad 2824.83$
(7) $3463 \quad 2680.74$
(8) $3791 \quad 2476.41$
(9) $714.8 \quad 2234.6$
(10) $539.1 \quad 1998.02$

(b) $X$-directional analysis

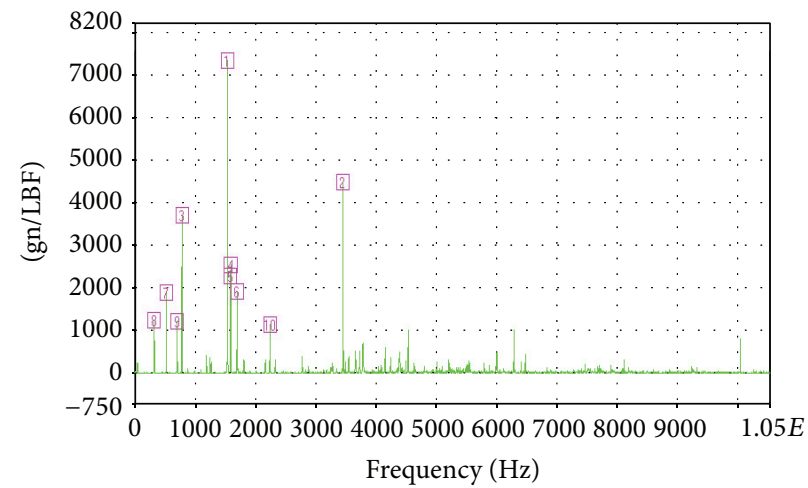

$H 1 \_2,1(f)$
X $\quad Y$
$\begin{array}{ll}X & Y\end{array}$
(1) $1550 \quad 7316.16$
(6) $1708 \quad 1919.71$
(2) $3457 \quad 4474.83$
(7) $536.1 \quad 1895.37$
(3) 796.93702 .72
(8) $336.9 \quad 1249.29$
(4) $1603 \quad 2541.25$
(9) $714.8 \quad 1202.34$
(5) $1597 \quad 2278.42$
(10) 22531124.08

(d) Z-directional analysis

FIGURE 12: Experimental analysis of the static state of the midspan shrouded blade. 

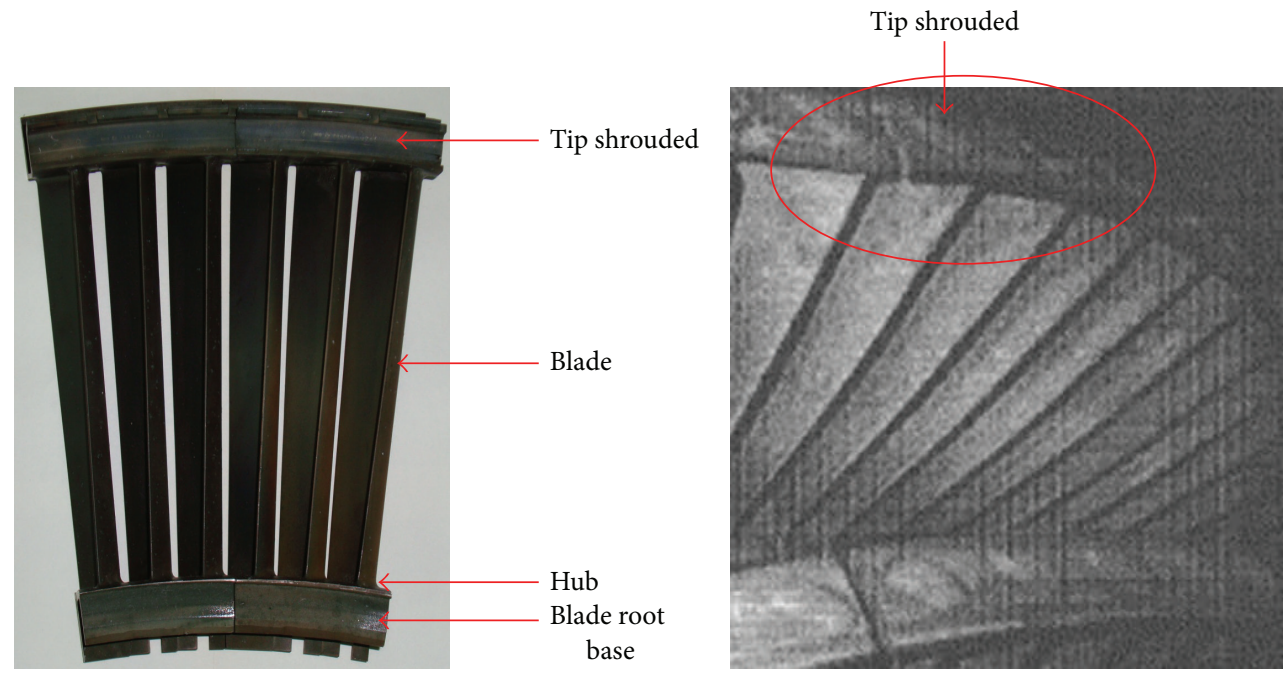

Figure 13: Tip-shrouded blade model.

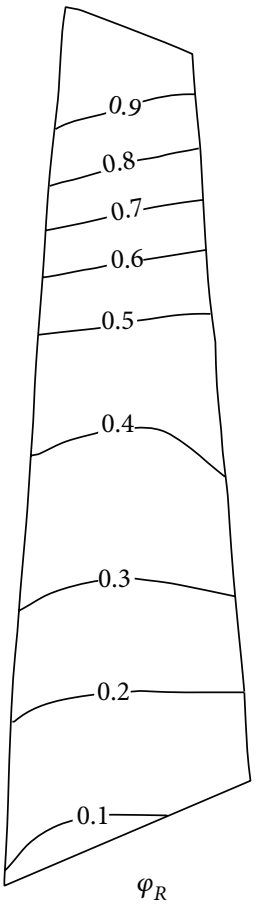

Mode 1

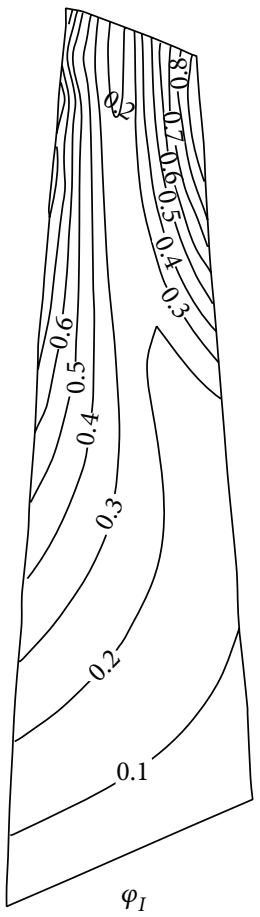

FIGURE 14: First system mode of the tip-shrouded blade.

\section{Results and Discussion}

5.1. Midspan Shrouded Blade. A midspan shrouded fan rotor is used for flutter analysis as a second option. Thirty-eight blades can be found in a fan rotor, with a midspan shroud on every blade, as seen in Figure 4. No physical connections exist between the midspan shrouds of all the blades of the common disk. However, all the shrouds make contact with one another during rotation due to the twisting of the blades.

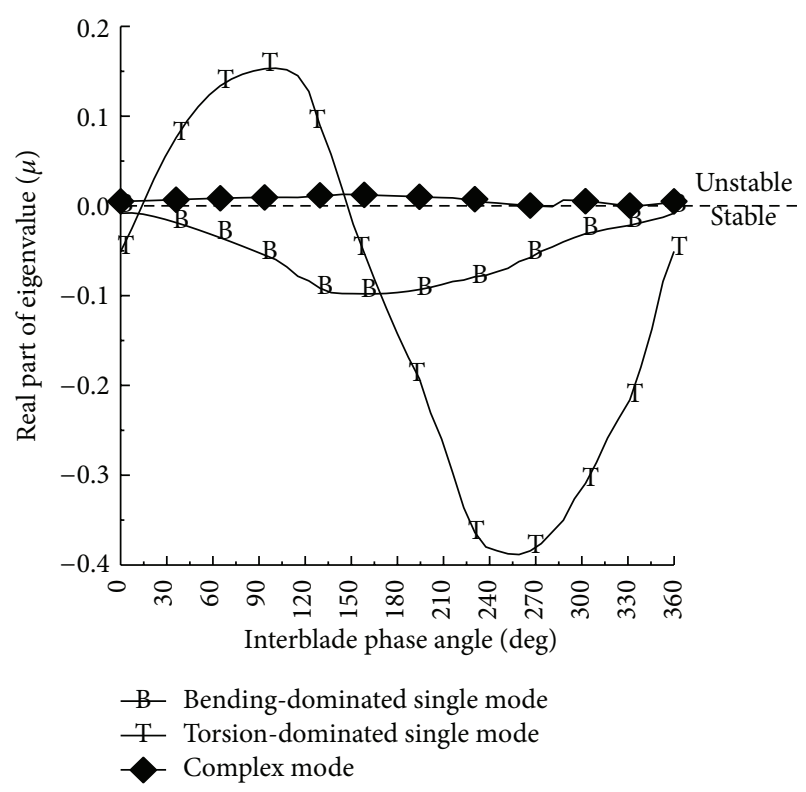

FIGURE 15: First system mode stability of the tip-shrouded blade.

5.1.1. Finite Element Model. The finite element model (excluding the shroud and dovetail) has 400 solid elements and 882 nodes, as seen in Figure 4. The first system mode has both bending and torsion mode components present in a single mode at the same time. The first system mode shape is decomposed into real and imaginary mode components, as shown in Figure 5.

5.1.2. Flutter Stability. Figure 5 shows the decomposed real and imaginary mode components for the first system mode, where the real mode component is torsion dominated and the imaginary mode component is bending dominated. 


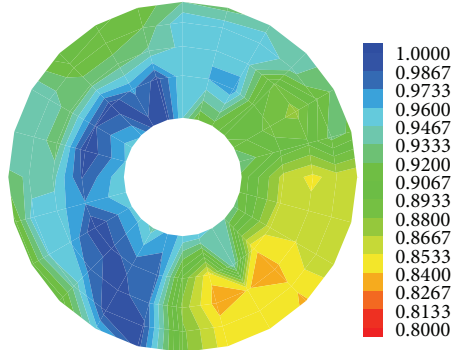

(a) Inlet total pressure (PTin/PTmax)

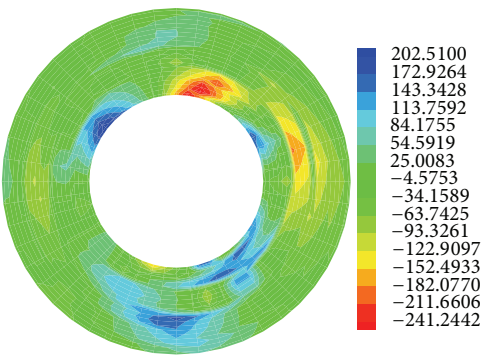

(d) Distorted tangential velocity ( $\mathrm{ft} / \mathrm{sec})$

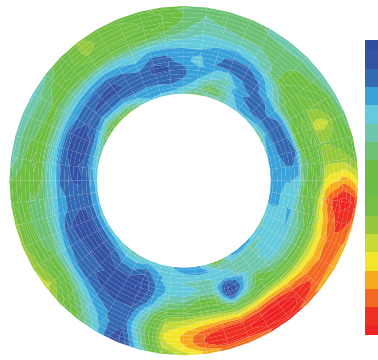

(g) Axial velocity (ft/sec)

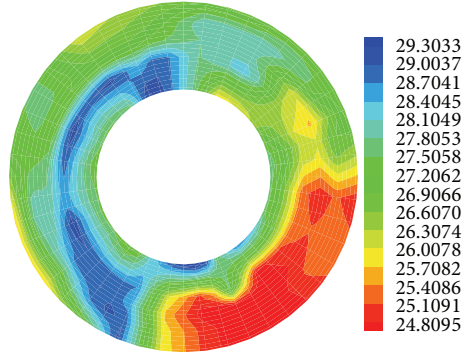

(b) Distorted total pressure (psi)

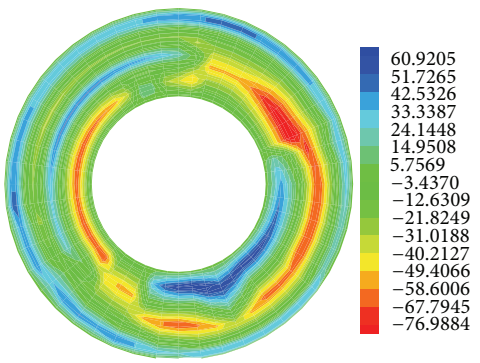

(e) Distorted radial velocity (ft/sec)

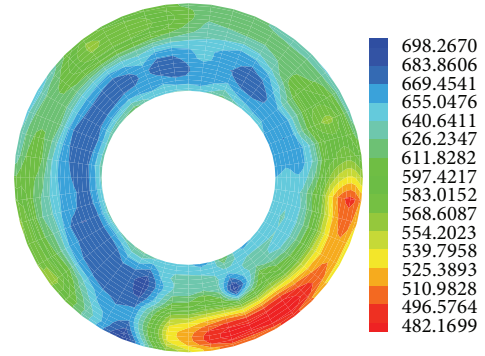

(h) Summary of axial and tangential velocities $(\mathrm{ft} / \mathrm{sec})$

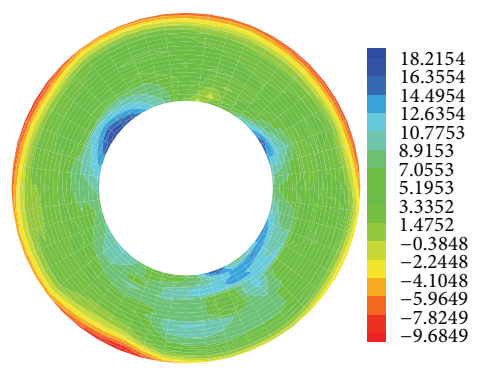

(j) Incidence angle (degree)

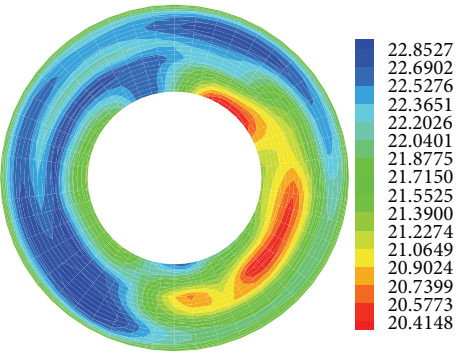

(c) Distorted static pressure (psi)

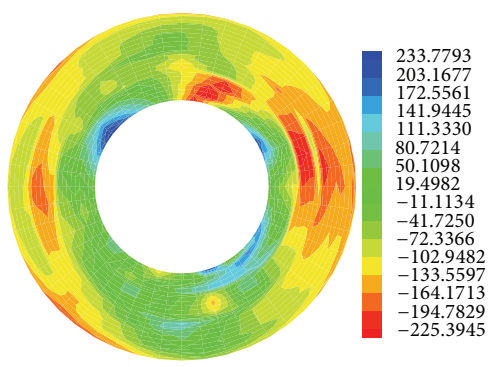

(f) Total tangential velocity (ft/sec)

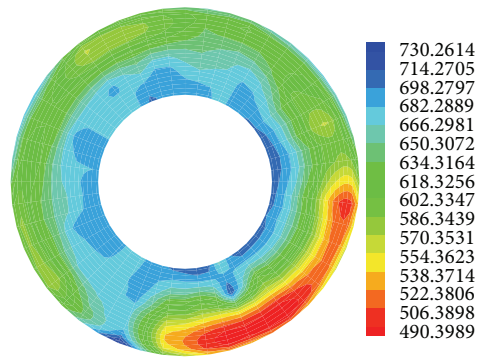

(i) Total velocity $(\mathrm{ft} / \mathrm{sec})$

FIGURE 16: Forcing function characteristics analysis of the tip-shrouded blade.

The single mode approach is used to analyze both the torsiondominated and the bending-dominated mode shapes by assuming a similar flow field. The stability results in Figure 6 show that the torsion-dominated mode shape is unstable and the bending-dominated mode shape is stable, in which this trend is similar. With the decomposed component modes of the first system combined into the system mode as input, complex mode analysis predicted that the first system mode is stable, as shown in Figure 6. Hence, with the torsion mode component being unstable and the bending mode component being stable, the combined system mode is predicted to be stable.

5.1.3. Forcing Functions. The inlet and distorted characteristics are found in six sectors, as shown in Figure 7. From the distorted characteristics, the ratio of interpolated span wise and input and computed PS, inlet total pressure, distorted 


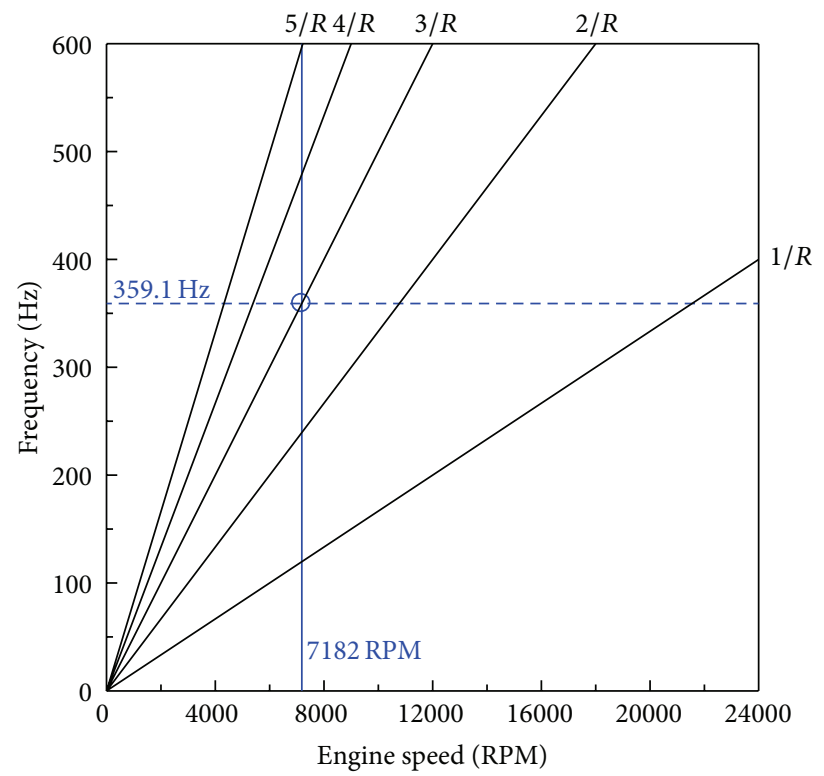

FIGURE 17: Campbell diagram for tip-shrouded blade.

static pressure, distorted tangential velocity, distorted radial velocity, total tangential velocity, axial velocity, and incidence angle characteristic results can be calculated for the six sectors, as shown in Figures 7(a) to 7(h).

Turbomachinery induces six sectors of the physical characteristics of the CFD flow field interaction between air flow and the rotor blade, when the air flow inlet has six groups of midspan shrouded blades. Low and high pressures, low and high velocities, and a difference of incidence angles have inlet and distorted characteristics in the interaction area. Structural forcing bending and torsion occur in the interaction areas. The entire forcing function output database calculates the rotor complex mode and single mode forced response prediction as well as revealing the lifetime limit.

5.1.4. Forced Response. Figure 8 shows the Campbell diagram for the midspan shrouded rotor blade. Figure 9 shows that the single and complex modes of the midspan shrouded fan rotor blade are verified.

Figure 10 shows a phase angle of $150^{\circ}$ for the first system mode $(255 \mathrm{~Hz})$ forced response analysis of the midspan shrouded fan rotor blade for the interblade. The diagram shows that the torsion mode has the highest forced response amplitude intensity, the complex mode has the lowest response intensity, and the bending mode is between the torsion and complex modes. The torsion and bending modes exceed the predicted results for the single mode approach.

5.1.5. Midspan Amplitude Intensity. The amplitude intensity of the midspan shrouded blade is explained in Figure 11. The amplitude intensity and forced response increase with increasing harmonics in the tip span. The amplitude intensity and forced response increase slightly with increasing harmonics in the midspan. The amplitude and forced response decrease slightly with increasing harmonics in the hubspan. Therefore, different blade forced responses and lifetimes are induced in the different blade span areas.

5.1.6. Midspan Blade Static State Experiment (Similarity of Blade Testing). The experimental frequency $(\mathrm{Hz})$ and amplitude analysis (gn/LBF) of the midspan shrouded static state hammer knock blade are shown in Figures 12(a) to 12(d). Figures $12(\mathrm{~b})$ to $12(\mathrm{~d})$ show that the $X$-directional main frequency is $1822 \mathrm{~Hz}$ and the first excitation is $539.1 \mathrm{~Hz}$, the $Y$-directional main frequency and the first excitation both are $539.1 \mathrm{~Hz}$, and the $Z$-directional main frequency is $1550 \mathrm{~Hz}$ and the first excitation is $336.9 \mathrm{~Hz}$ under free-free testing.

5.2. Tip-Shrouded Blade. A tip-shrouded fan rotor is used for flutter analysis. Fifty blades can be found in a fan rotor, with a tip-shrouded on every blade, as shown in Figure 13. The tip-shrouded of all the blades have no physical connections, and all the shrouds are in contact during rotation due to the twisting of the blades.

5.2.1. Finite Element Model. As shown in Figure 13, the finite element model (excluding the shroud and dovetail) has 300 solid elements and 462 nodes. Similarly, the first system mode has bending and torsion mode components present in a single mode at the same time.

5.2.2. Flutter Stability. For the first system mode, Figure 14 shows the decomposed real and imaginary mode components, where the real mode component is bending dominated and the imaginary mode component is torsion dominated. The single mode approach is used to analyze both the torsiondominated and the bending-dominated mode shapes. The 
Frequency $=359.1 \mathrm{~Hz}$
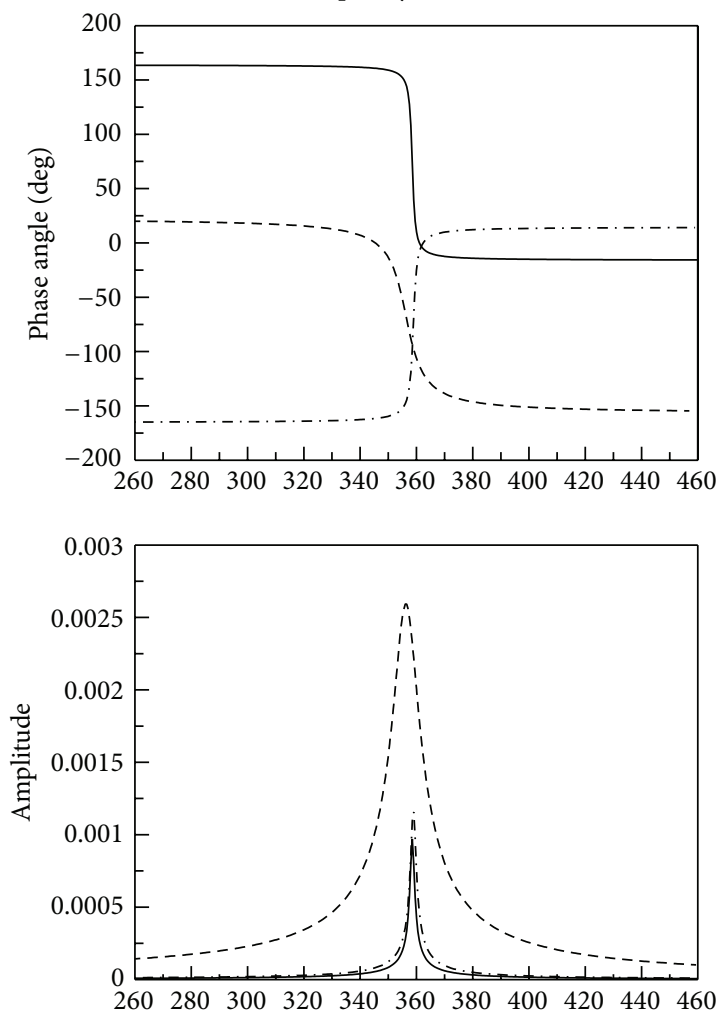

(a) $\mathrm{GA}=0$ degree
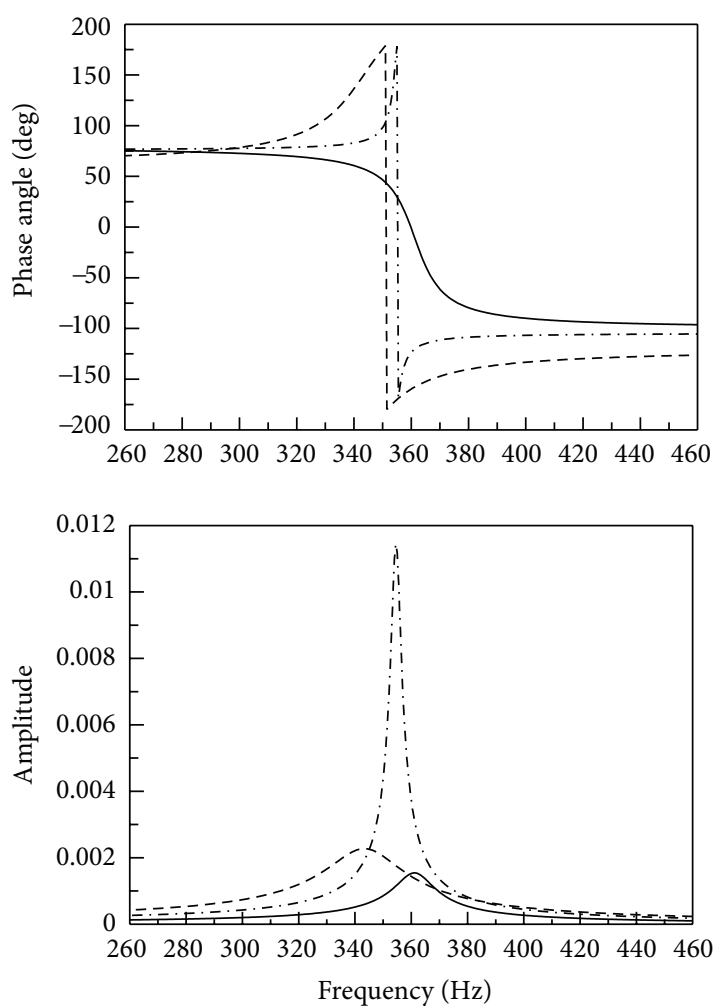

— Bending mode

- - - Torsion mode

(c) $\mathrm{GA}=120$ degree
Frequency $=359.1 \mathrm{~Hz}$
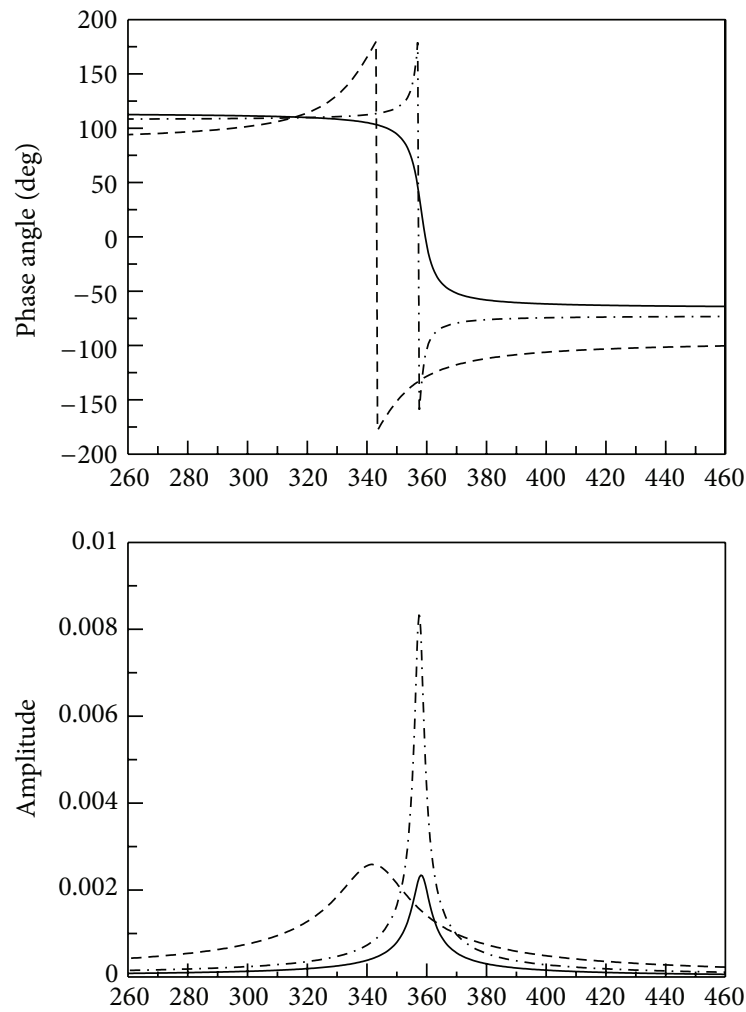

(b) $\mathrm{GA}=60$ degree
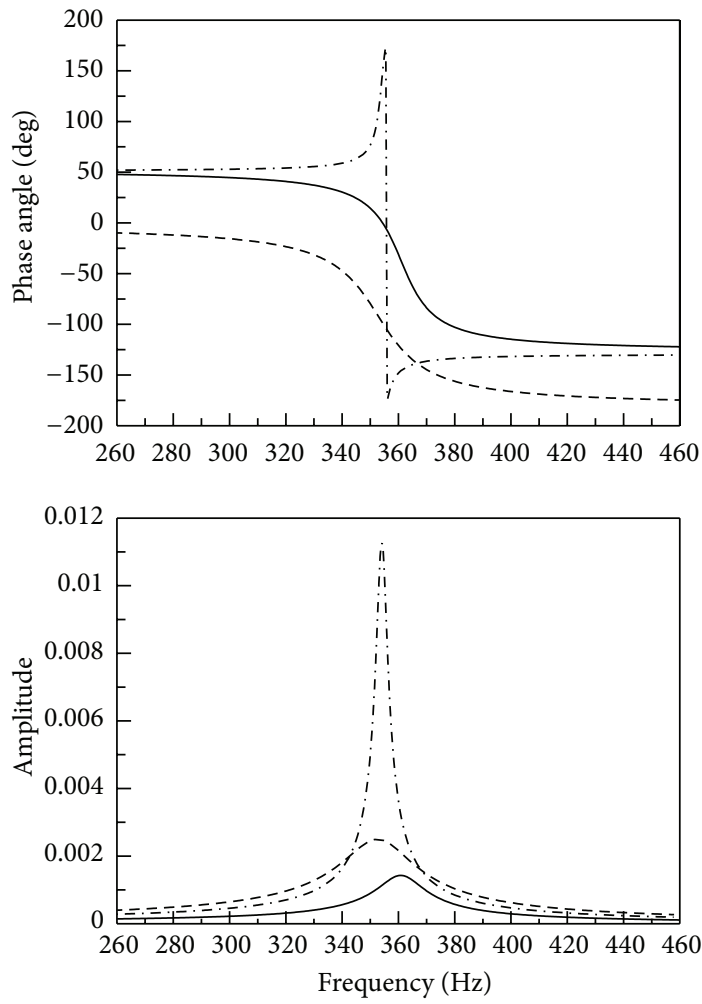

- Bending mode ...- Complex mode - - - Torsion mode

(d) $\mathrm{GA}=180$ degree

Figure 18: Continued. 

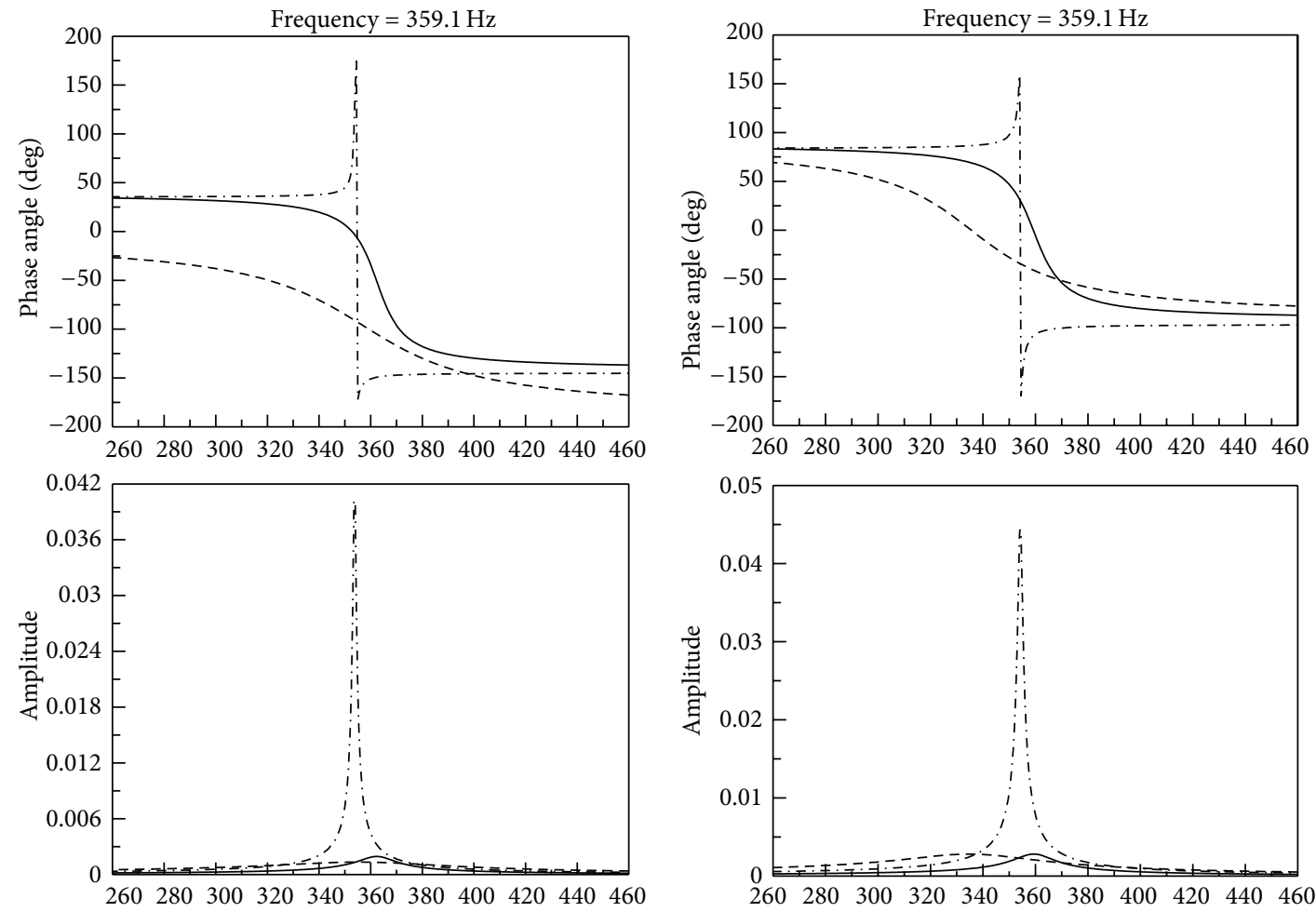

(e) $\mathrm{GA}=240$ degree

(f) $\mathrm{GA}=300$ degree
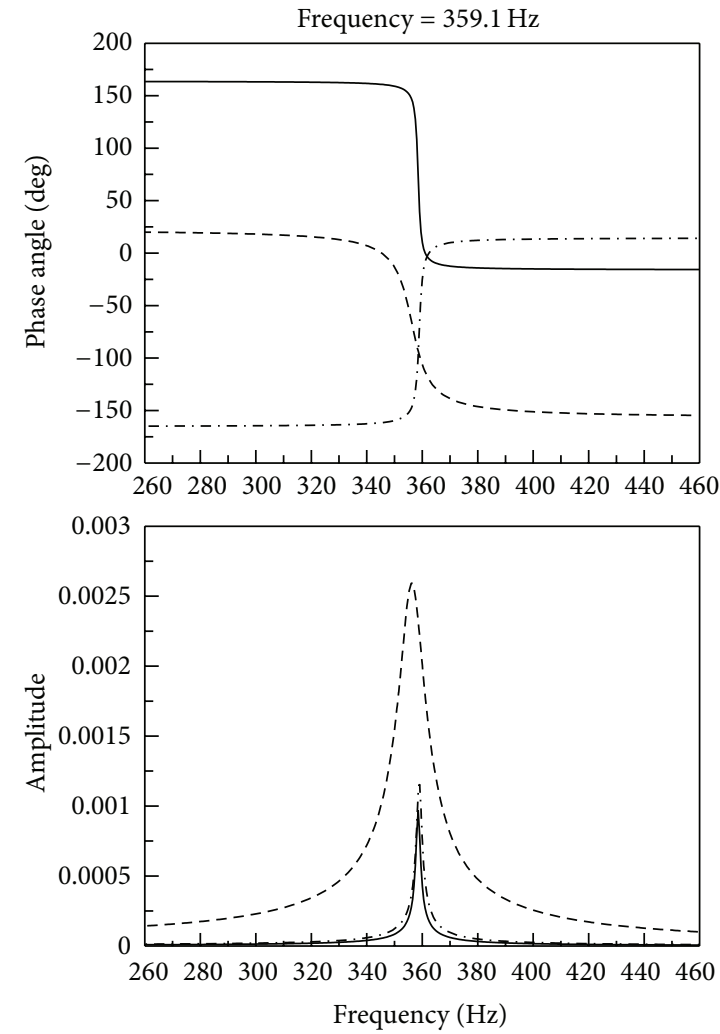

$\begin{array}{lll}\text { - } & \text { Bending mode } \\ ---\cdot-\text { Torsion mode } & & \end{array}$

(g) $\mathrm{GA}=360$ degree

FIGURE 18: First system mode $(359.1 \mathrm{~Hz})$ forced response for interblade phase angles of $0,60,120,180,240,300$, and $360^{\circ}$ of the tip-shrouded blade. 

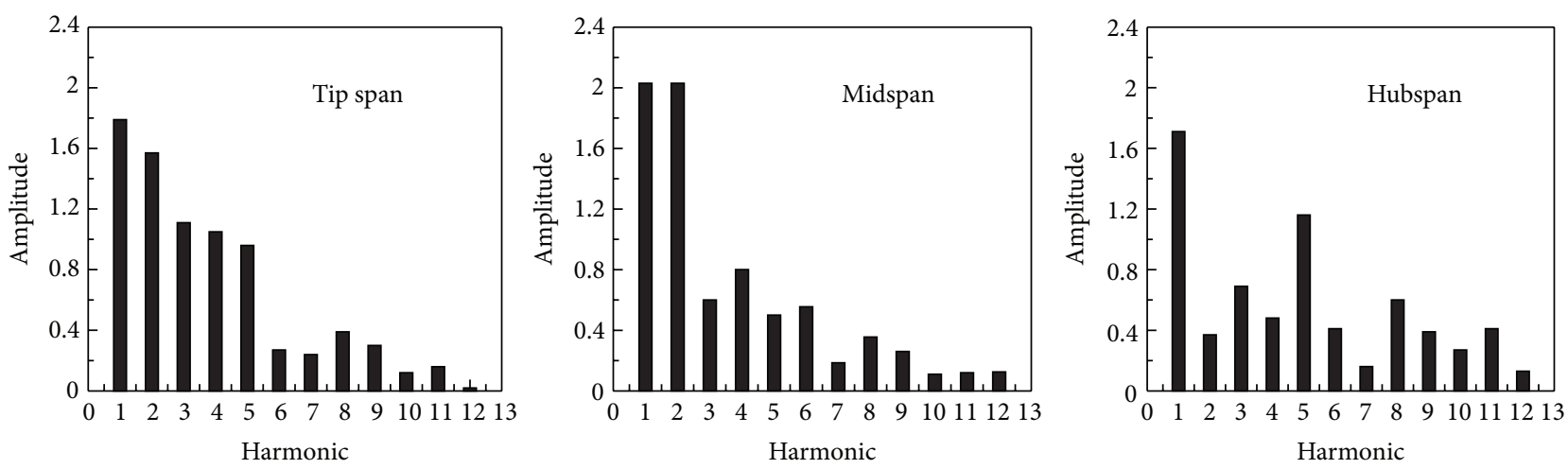

FIgURE 19: Amplitude intensity of tip-shrouded blade.

stability results in Figure 15 show that the torsion-dominated mode shape is unstable and the bending-dominated mode shape is stable. With the decomposed component modes of the first system being combined into the system mode as input, the complex mode flutter analysis is used to predict the mode stability of the first system. With the torsion mode component being unstable and the bending mode component being stable, the combined system complex mode is predicted to be unstable.

5.2.3. Forcing Functions. The inlet and distorted characteristics are shown in Figure 16. From the distorted characteristics, the inlet total pressure, distorted total pressure, distorted static pressure, distorted tangential velocity, distorted radial velocity, total tangential velocity, axial velocity, summary of axial and tangential velocities, total velocity, and incidence angle characteristic results can be calculated as shown in Figures 16(a) to $16(j)$.

Turbomachinery will induce flow field interaction characteristics between air flow and rotor blade when air flow inlet tip-shrouded blade. The inlet and distorted pressures, the difference of velocities, and the difference of incidence angles exhibit inlet and distorted characteristic distribution in the interaction area. Structural forcing bending and torsion are observed in some interaction areas. The forcing function output database can calculate forced response of the complex and single modes of the rotor as well as revealing the lifetime limit.

5.2.4. Forced Response. Figure 17 shows the Campbell diagram for the tip-shrouded blade. Figure 18 shows the forced response analysis of the tip-shrouded first system mode $(359.1 \mathrm{~Hz})$ at interblade phase angles of $0,60,120,180$, 240,300 , and $360^{\circ}$. The forced response diagram shows the complex mode, which has the highest response amplitude intensity, the bending mode, which has the lowest response intensity, and the torsion mode, which has intensity between that of the bending and complex modes. The single mode approach underpredicted the torsion and bending modes.

5.2.5. Tip-Shrouded Amplitude Intensity. The amplitude intensity of the tip-shrouded blade is explained in Figure 19.
The amplitude intensity decreases slowly and the forced response increases and decreases slowly when the harmonic increases in the tip span. The amplitude intensity decreases rapidly and the forced response increases and decreases quickly when the harmonic increases in the midspan. The amplitude intensity and the forced response decrease and increase for one cycle when the harmonic increases in the hubspan. This condition induces different blade forced responses and lifetimes in the different blade span areas.

5.2.6. Tip-Shrouded Blade Static State Experiment (Similarity of Blade Testing). The analysis of tip-shrouded blade static state experimental frequency and amplitude for the lowpressure and the high-pressure stage blades is shown in Figures 20 and 21, respectively.

Figures 20(a) to 20(d) show the experimental frequency $(\mathrm{Hz})$ and amplitude $(\mathrm{gn} / \mathrm{LBF})$ of the tip-shrouded static state knock excited blade frequency in the low-pressure stage blade. The $X$-directional main frequency is $4491 \mathrm{~Hz}$ and the first excitation is $993.2 \mathrm{~Hz}$; the $Y$-directional main frequency and the first excitation both are $2616 \mathrm{~Hz}$; and the $Z$-directional main frequency and the first excitation both are $1002 \mathrm{~Hz}$ under free-free testing.

Figures 21(a) to 21(d) show the experimental frequency $(\mathrm{Hz})$ and amplitude $(\mathrm{gn} / \mathrm{LBF})$ of the tip-shrouded static state knock excited blade frequency in the low-pressure stage blade. The $X$-directional main frequency is $3768 \mathrm{~Hz}$ and the first excitation is $17.58 \mathrm{~Hz}$; the $Y$-directional main frequency is $3768 \mathrm{~Hz}$ and the first excitation is $11.72 \mathrm{~Hz}$, and the $Z$ directional main frequency is $20.51 / 1462 / 1562 \mathrm{~Hz}$ and the first excitation is $35.16 / 82.03 \mathrm{~Hz}$ under free-free testing.

\section{Conclusion}

Both the complex mode and single mode approaches have been individually developed to predict shrouded rotor blade flutter and forced response. A modal aeroelastic solution is also implemented. This solution models three-dimensional aeroelastic effects by calculating unsteady aerodynamic loads on two-dimensional strips, which are stacked from hub to tip along the span of the blade. A classic two-dimensional 

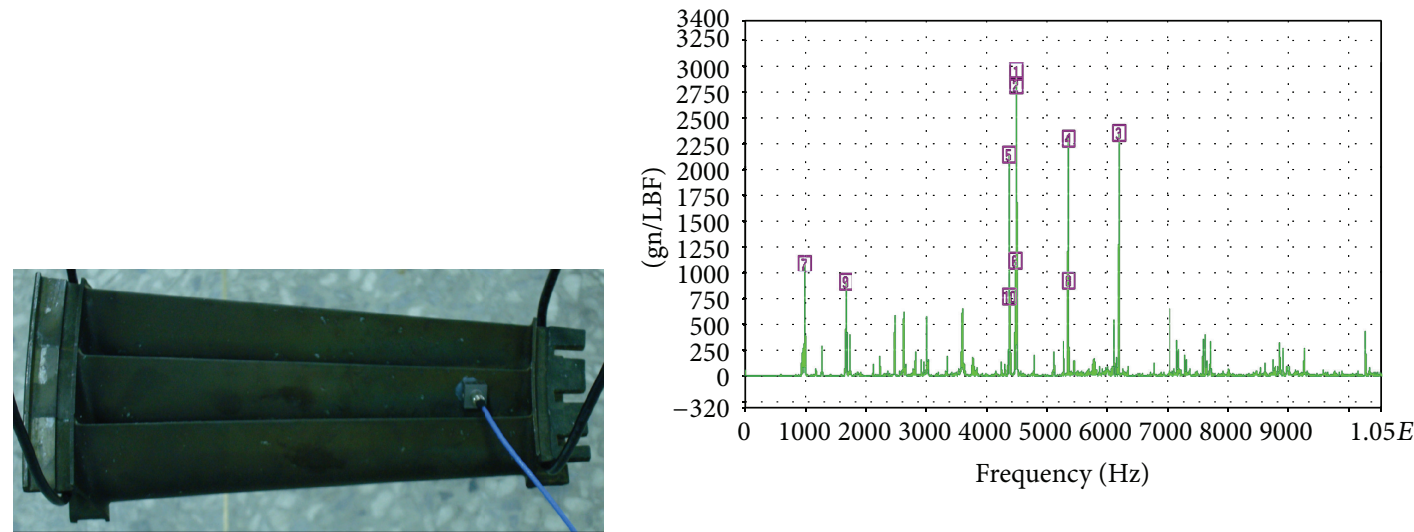

$\begin{array}{ccrcc} & X & Y & H 1 \_2,1(f) & \\ \text { (1) } 4491 & 2922.05 & \text { (6) } 4471 & 1112.95 \\ \text { (2) } 4485 & 2786.41 & \text { (7) } 993.2 & 1078.88 \\ \text { (3) } 6182 & 2332.94 & \text { (8) } 5355 & 900.646 \\ \text { (4) } 5347 & 2281.99 & \text { (9) } 1667 & 896.991 \\ \text { (5) } 4368 & 2136.31 & \text { (10) } 4377 & 753.546\end{array}$

(a) Tip-shrouded blade experimental testing

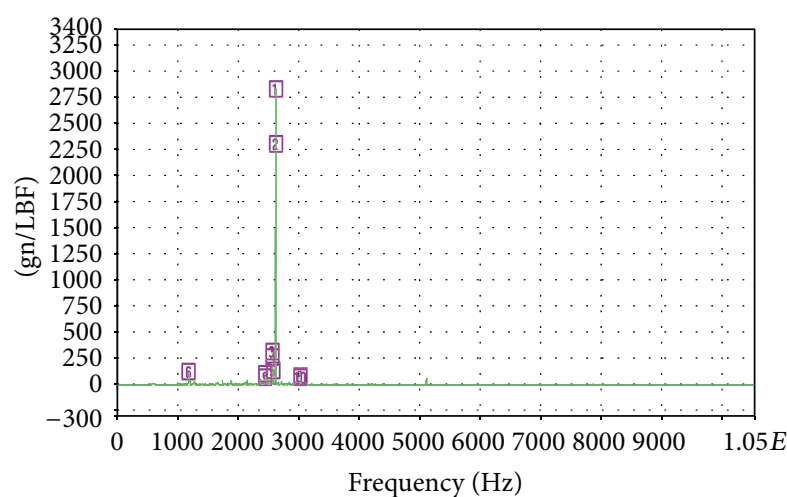

\begin{tabular}{clrrl} 
& \multicolumn{1}{c}{ X } & \multicolumn{1}{c}{ H1_2, $1(f)$} & & \\
(1) 2616 & 2830.82 & (6) 1175 & 129.856 \\
(2) 2622 & 2304.37 & (7) 2446 & 104.056 \\
(3) 2561 & 316.546 & (8) 3015 & 80.5096 \\
(4) 2566 & 270.652 & (9) 2452 & 74.0589 \\
(5) 2572 & 137.56 & (10) 3021 & 69.397
\end{tabular}

(c) $Y$-directional analysis (b) X-directional analysis

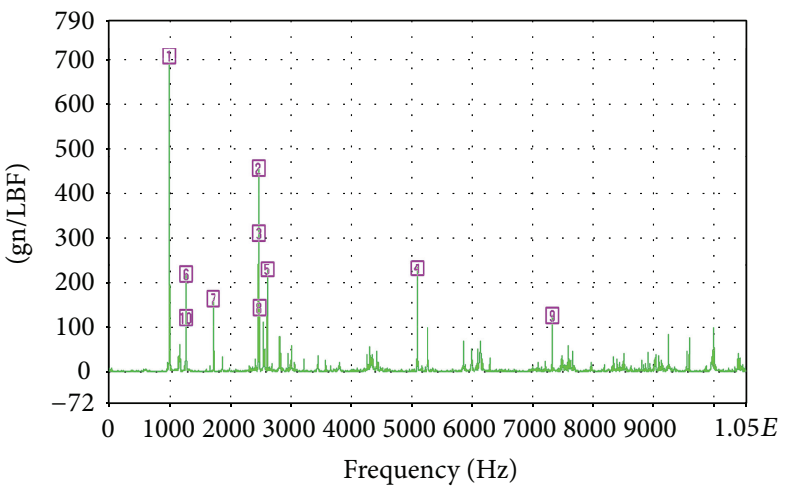
X $\quad Y$
$H 1 \_2,1(f)$
(1) $1002 \quad 706.798$

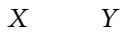
(2) $2476 \quad 456.741$
(6) $1277 \quad 217.801$
(3) 2484311.401
(7) $1729 \quad 162.135$
(4) $5098 \quad 231.142$
(8) $2490 \quad 141.077$
(9) $7339 \quad 124.578$
(5) $2622 \quad 230.149$
(10) $1271 \quad 120.22$

(d) Z-directional analysis

FIGURE 20: Experimental analysis for low-pressure stage tip-shrouded blade.

kernel function theory is utilized to calculate the unsteady subsonic, transonic, and supersonic aerodynamics, which is due to blade motion.

Finite element method is used to provide system mode shapes and frequencies. The shrouded rotor blade design causes complex blade mode shapes and, in some cases, has both bending and torsion mode components present in a single mode at the same time. Therefore, complex (cyclic symmetry) and single mode analyses are developed to predict shrouded rotor blade flutter with the combined system mode shapes of bending and torsion.
The complex and single mode analyses are useful tools for evaluating the forced response of the shrouded rotor blade, especially for cases of combined bending and torsion mode shapes. With the use of the single mode approach for the torsion and bending modes, the midspan and tipshrouded rotor blades are over- and underpredicted by forced response analysis, respectively. With the use of the complex mode approach, the midspan and tip-shrouded rotor blades are under- and overpredicted by forced response analysis, respectively. The complex mode approach can be improved to produce the same results as the single mode 


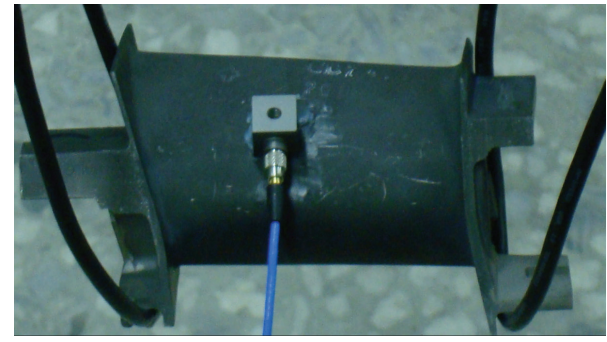

(a) Tip-shrouded blade experimental testing

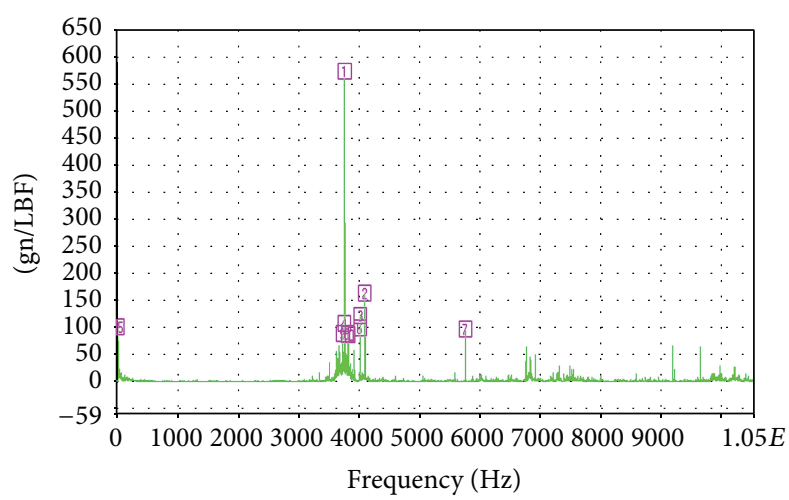

$H 1 \_2,1(f)$
$\begin{array}{cc}X & Y \\ \text { (1) } 3768 & 572.197\end{array}$

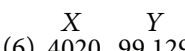
(2) $4099 \quad 161.356$
(7) 576397.0625
(3) $4025 \quad 120.973$
(8) $3814 \quad 89.0992$
(4) $3759 \quad 107.138$
(9) 373587.6078
(5) 11.72100 .911
(10) 382687.2069

(c) $Y$-directional analysis

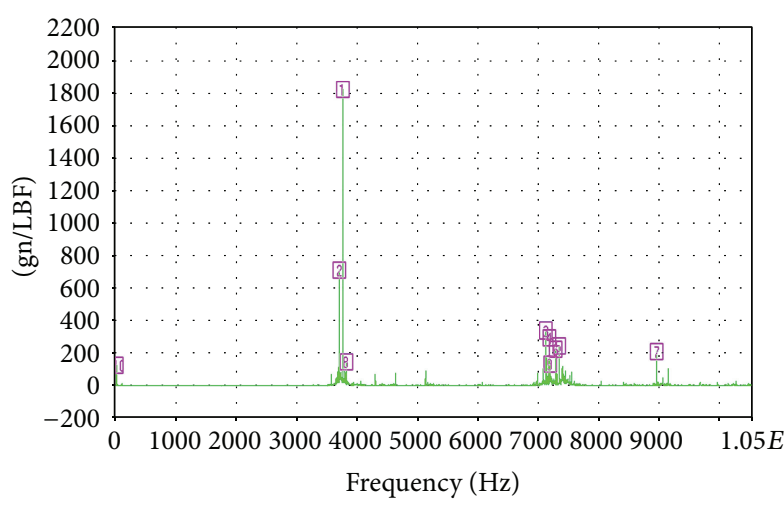

$H 1 \_2,1(f)$

$\begin{array}{cccc}X & Y & & X \\ \text { (1) } 3768 & 1814.76 & \text { (6) } 7295 & 220.34 \\ \text { (2) } 3712 & 709.456 & \text { (7) } 8965 & 209.307 \\ \text { (3) } 7134 & 336.767 & \text { (8) } 3820 & 146.707 \\ \text { (4) } 7181 & 289.957 & \text { (9) } 7198 & 131.98 \\ \text { (5) } 7345 & 244.614 & \text { (10) } 17.58 & 123.21\end{array}$

(b) $X$-directional analysis

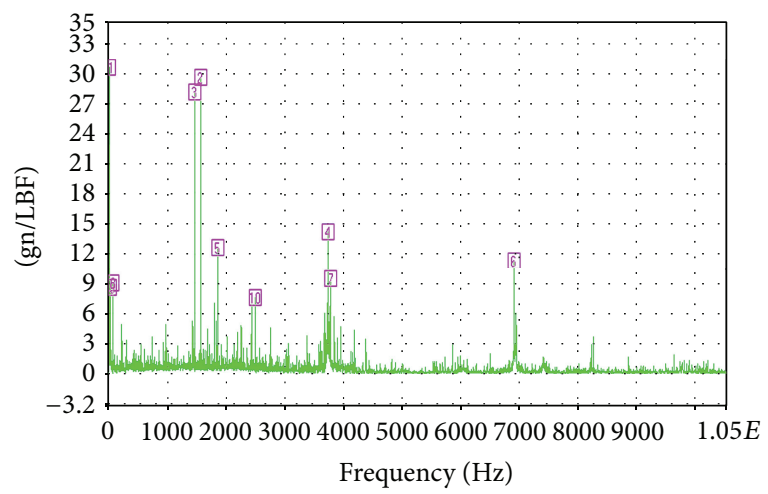

$H 1 \_2,1(f)$
$\begin{array}{cc}X & Y \\ \text { (1) } 20.51 & 30.4498\end{array}$
$\begin{array}{cc}X & Y \\ 6920 & 112628\end{array}$
(2) $1562 \quad 29.4733$
(7) $3785 \quad 9.33286$
(3) $1462 \quad 28.0011$
(8) 82.038 .96547
(4) $3735 \quad 14.1039$
(9) 35.168 .47892
(5) $1849 \quad 12.5666$
(10) 24997.52265

(d) Z-directional analysis

FIGURE 21: Blade static state experimental analysis for high-pressure stage tip-shrouded blade.

approach. Therefore, the analyses conducted by using the two approaches can obtain complementary results.

\section{Conflict of Interests}

The author declares that there is no conflict of interests regarding the publication of this paper.

\section{Acknowledgment}

The author would like to thank the Engineering Division of the National Science Council of the Republic of China,
Taiwan, for financially supporting this research under Contract nos. NSC 100-2218-E-167-002, NSC 101-2221-E-167-013, and NSC 102-2622-E-167-022-CC3.

\section{References}

[1] H. W. D. Chiang and R. E. Kielb, "Analysis system for blade forced response," ASME Journal of Turbomachinery, vol. 115, no. 4, pp. 762-770, 1993.

[2] H. W. D. Chiang and M. G. Turner, "Compressor blade forced response due to downstream vane-strut potential interaction," ASME Journal of Turbomachinery, vol. 118, no. 1, pp. 134-142, 1996. 
[3] D. V. Murthy and G. L. Stefko, "FREPS-A forced response prediction system for turbomachinery blade rows," AIAA Paper 92-3072, 1992.

[4] R. E. Kielb and H. W. D. Chiang, "Recent advancements in turbomachinery forced response analyses," in Proceeding of the 30th AIAA Aerospace Science Meeting, AIAA Paper 92-0012, Reno, Nev, USA, January 1992.

[5] M. S. Izsak and H. W. D. Chiang, "Turbine and compressor wake modeling for blade forced response," ASME Paper 93-GT-148, 1993.

[6] S. R. Manwaring and D. C. Wisler, "Unsteady aerodynamics and gust response in compressors and turbines," ASME Journal of Turbomachinery, vol. 115, no. 4, pp. 724-740, 1993.

[7] S. R. Manwaring, D. C. Rabe, C. B. Lorence, and A. R. Wadia, "Inlet distortion generated forced response of a low-aspect-ratio transonic fan," ASME Journal of Turbomachinery, vol. 119, no. 4, pp. 665-676, 1997.

[8] K. Willcox, J. Peraire, and J. D. Paduano, "Application of model order reduction to compressor aeroelastic models," ASME Paper 2000-GT-0377, 2000.

[9] K. C. Hall and P. D. Silkowski, "The influence of neighboring blade rows on the unsteady aerodynamic response of cascades," ASME Journal of Turbomachinery, vol. 119, no. 1, pp. 85-92, 1997.

[10] P. D. Silkowski and K. C. Hall, "A coupled mode analysis of unsteady multistage flows in turbomachinery," ASME Journal of Turbomachinery, vol. 120, no. 3, pp. 410-421, 1998.

[11] S. R. Manwaring and S. Fleeter, "Rotor blade unsteady aerodynamic gust response to inlet guide vane wakes," ASME Paper 91-GT-129, 1991.

[12] R. Phibel and L. di Mare, "Comparison between a CFD and three-control-volume model for labyrinth seal flutter predictions," in Proceedings of the ASME TURBO EXPO: Power for Land, Sea, and Air, GT2011-46281, ASME International Gas Turbine Institute, Vancouver, Canada, June 2011.

[13] C. Peng, "Tip running clearances effects on tip vortices induced axial compressor rotor flutter," in Proceedings of the ASME TURBO EXPO: Power for Land, Sea, and Air, GT2011-45504, ASME International Gas Turbine Institute, Vancouver, Canada, June 2011.

[14] P. Vasanthakumar, "Computation of aerodynamic damping for flutter analysis of a transonic fan," in Proceedings of the ASME TURBO EXPO: Power for Land, Sea, and Air, GT2011-46597, ASME International Gas Turbine Institute, Vancouver, Canada, June 2011.

[15] R. Antona, R. Corral, J. M. Gallardo, and C. Martel, "Effect of the structural coupling on the flutter onset of a sector of flowpressure turbine vanes," in Proceedings of the ASME TURBO EXPO: Power for Land, Sea, and Air, GT2010-23037, ASME International Gas Turbine Institute, Glasgow, UK, June 2010.

[16] R. Srivastava, J. Panovsky, R. Kielb, L. Virgin, and K. Ekici, "Non-linear flutter in fan stator vanes with time dependent fixity," in Proceedings of the ASME TURBO EXPO: Power for Land, Sea, and Air, GT2010-22555, ASME International Gas Turbine Institute, Glasgow, UK, June 2010.

[17] L. Li and P. Wang, "Evaluation of high-order resonance of blade under wake excitation," in Proceedings of the ASME TURBO EXPO: Power for Land, Sea, and Air, GT2010-23148, ASME International Gas Turbine Institute, Glasgow, UK, June 2010.

[18] E. Johann, B. Muck, and J. Nipkau, "Experimental and numerical flutter investigation of the 1st stage rotor in 4-stage high speed compressor," in Proceedings of the ASME TURBO EXPO: Power for Land, Sea, and Air, GT2008-50698, ASME International Gas Turbine Institute, Berlin, Germany, June 2008.

[19] O. G. McGee III and C. Fang, "A reduced-order integrated design synthesis for the three-dimensional tailored vibration response and flutter control of high-bypass shroudless fans," in Proceedings of the ASME TURBO EXPO: Power for Land, Sea, and Air, GT2008-51479, ASME International Gas Turbine Institute, Berlin, Germany, June 2008.

[20] M. Aotsuka, N. Tsuchiya, Y. Horiguchi, O. Nozaki, and K. Yamamoto, "Numerical simulation of transonic fan flutter with $3 \mathrm{D}$ N-S CFD code," in Proceedings of the ASME TURBO EXPO: Power for Land, Sea, and Air, GT2008-50573, ASME International Gas Turbine Institute, Berlin, Germany, June 2008.

[21] A. Zemp, R. S. Abhari, and M. Schleer, "Experimental investigation of forced response impeller blade vibration in a centrifugal compressor with variable inlet guide vanes part 1: blade damping," in Proceedings of the ASME TURBO EXPO: Power for Land, Sea, and Air, GT2011-46289, ASME International Gas Turbine, Vancouver, Canada, June 2011.

[22] A. Zemp, R. S. Abhari, and M. Schleer, "Experimental investigation of forced response impeller blade vibration in a centrifugal compressor with variable Inlet guide vanes part 2: forcing function and FSI computations," in Proceedings of the ASME TURBO EXPO: Power for Land, Sea, and Air, GT2011-46290, ASME International Gas Turbine Institute, Vancouver, Canada, June 2011.

[23] B. Zhou, A. Mujezinovic, A. Coleman, W. Ning, and A. Ansari, "Forced response prediction for steam turbine last stage blade subject to low engine order excitation," in Proceedings of the ASME TURBO EXPO: Power for Land, Sea, and Air, GT201146856, Vancouver, Canada, June 2011.

[24] A. Hohi, B. Kriegesmann, J. Wallaschek, and L. Panning, “The influence of blade properties on the forced response of mistuned bladed disks," in Proceedings of the ASME TURBO EXPO: Power for Land, Sea, and Air, GT2011-46826, ASME International Gas Turbine Institute, Vancouver, Canada, June 2011.

[25] C. Siewert and H. Stuer, "Forced response analysis of mistuned turbine bladings," in Proceedings of the ASME TURBO EXPO: Power for Land, Sea, and Air, GT2010-23782, ASME International Gas Turbine Institute, Glasgow, UK, June 2010.

[26] C. Heinz, M. Schatz, M. V. Casey, and H. Stuer, "Experimental and analysis investigations of a low pressure model turbine during forced response excitation," in Proceedings of the ASME TURBO EXPO: Power for Land, Sea, and Air, GT2010-22146, ASME International Gas Turbine Institute, Glasgow, UK, June 2010.

[27] V. Kharyton, J. P. Laine, F. Thouverez, and O. Kucher, "Simulation of tip-timing measurements of a cracked bladed disk forced response," in Proceedings of the ASME TURBO EXPO: Power for Land, Sea, and Air, GT2010-22388, ASME International Gas Turbine Institute, Glasgow, UK, June 2010.

[28] E. P. Petrov, "Reduction of forced response levels for bladed discs by mistuning: overview of the phenomenon," in Proceedings of the ASME TURBO EXPO: Power for Land, Sea, and Air, GT2010-23299, ASME International Gas Turbine Institute, Glasgow, UK, June 2010.

[29] W. W. Gu, Z. Xu, and Q. Lv, "Forced response of shrouded blades with intermittent dry friction force," in Proceedings of the ASME TURBO EXPO: Power for Land, Sea, and Air, GT2008-51041, 
ASME International Gas Turbine Institute, Berlin, Germany, June 2008.

[30] J. S. Green, "Forced response of a large civil fan assembly," in Proceedings of the ASME TURBO EXPO: Power for Land, Sea, and Air, GT2008-50319, ASME International Gas Turbine Institute, Berlin, Germany, June 2008.

[31] S. Dhandapani, M. Vahdati, and M. Imregun, "Forced response and surge behaviour of IP core-compressors with ICE-damaged rotor blades," in Proceedings of the ASME TURBO EXPO: Power for Land, Sea, and Air, GT2008-50335, ASME International Gas Turbine Institute, Berlin, Germany, June 2008.

[32] L. Lin, Z. Luo, and J. Xiang, "Simplified modeling and parameters analysis on whirl flutter of tiltrotor," in Proceeding of the 8th Cross-Straits Conference on Aeronautics and Astronautics, pp. 282-289, Beijing, China, September 2012.

[33] J. Tang, C. Xie, and C. Yang, "Vibration and flutter analysis of aircraft wing using equivalent-plate models," in Proceeding of the 8th Cross-straits Conference on Aeronautics and Astronautics, pp. 311-318, Beijing, China, September 2012.

[34] H. Zhang, C. Xie, and C. Yang, "Application of HHT and flutter margin method for flutter boundary prediction," in Proceeding of the 8th Cross-straits Conference on Aeronautics and Astronautics, pp. 335-342, Beijing, China, September 2012.

[35] R. Rzadkowski, Flutter of Turbine Rotor Blades in Inviscid Flow, AMW Wewn. 1050/2004, Akademia Marynarki Wojennej, Gdynia, Poland, 2004.

[36] S. N. Smith, Discrete Frequency Sound Generation in Axial Flow Turbomachines, R \& M, 3709, British Aeronautical Research Council, London, UK, 1972.

[37] F. Lane, "System mode shapes in the flutter of compressor blade rows," Journal of the Aeronautical Science, vol. 23, no. 1, pp. 5466, 1956.

[38] A. V. Srinivasan, "Flutter and resonant vibration characteristics of engine blades," ASME Journal of Engineering For Gas Turbines and Power, vol. 119, no. 1, pp. 742-775, 1997.

[39] F. Moyroud, J. G. Richardet, and T. Fransson, "A modal coupling for fluid and structure analyses of turbomachine flutter: application to a fan stage," ASME Paper 96-GT-335, 1996.

[40] E. F. Crawley, "Aeroelastic formulation for tuned and mistuned rotors," in AGARD Manual on Aeroelasticity in Axial-Flow Turbomachines, vol. 2, Structural Dynamics and Aeroelasticity, 1988.

[41] K. C. Hall and P. D. Silkowski, "The influence of neighboring blade rows on the unsteady aerodynamic response of cascades," ASME Journal of Turbomachinery, vol. 119, no. 1, pp. 85-92, 1997.

[42] C. N. Hsu, Turbomachinery blading flutter and forced response due to unsteady aerodynamics [Ph.D. Dissertation], National Tsing Hua University, 2005.

[43] H. W. D. Chiang, C. Chen, and C. Hsu, "Prediction of shrouded turbomachinery blade flutter by a complex mode analysis," International Journal of Turbo and Jet Engines, vol. 22, no. 2, pp. 89-101, 2005.

[44] H. W. D. Chiang, C. C. Chen, C. N. Hsu, G. C. Tsai, and K. L. Koai, "An investigation of turbomachinery shrouded rotor blade flutter," in Proceedings of the ASME TURBO EXPO: Power for Land, Sea, and Air, GT2003-38311, ASME International Gas Turbine Institute, Atlanta, Ga, USA, June 2003.

[45] H. W. D. Chiang and C. N. Hsu, "Prediction of shrouded turbomachinery blade forced response by a complex mode analysis," in Proceedings of the GT ASME IGTI Turbo Expo: Power for Land, Sea and Air, GT2006-90112, Barcelona, Spain, May 2006.

[46] H. W. D. Chiang and C. N. Hsu, "Turbomachine shrouded rotor blade forced response analysis," International Journal of Turbo and Jet Engines, vol. 25, no. 3, pp. 179-188, 2008. 


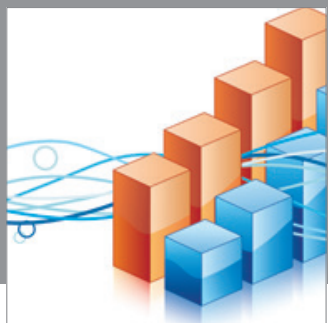

Advances in

Operations Research

mansans

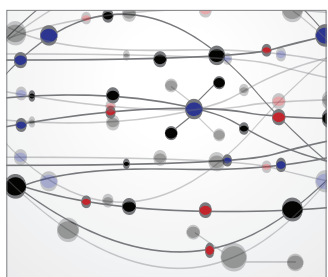

The Scientific World Journal
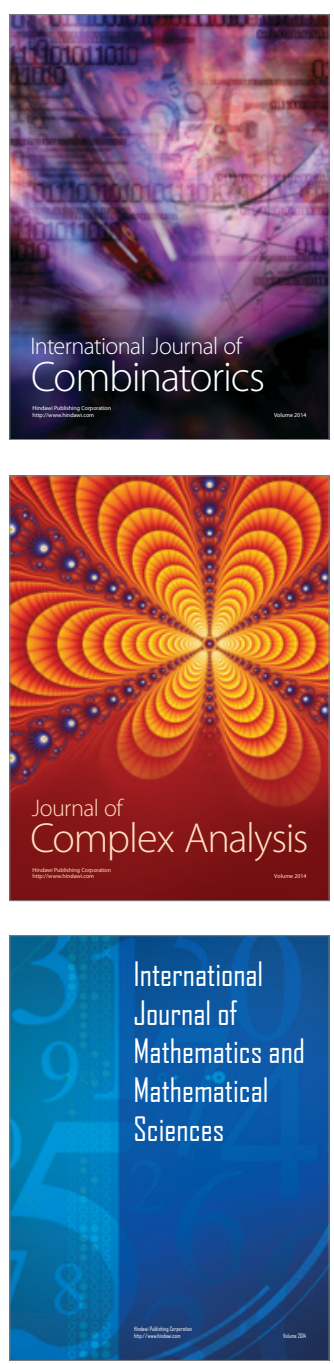
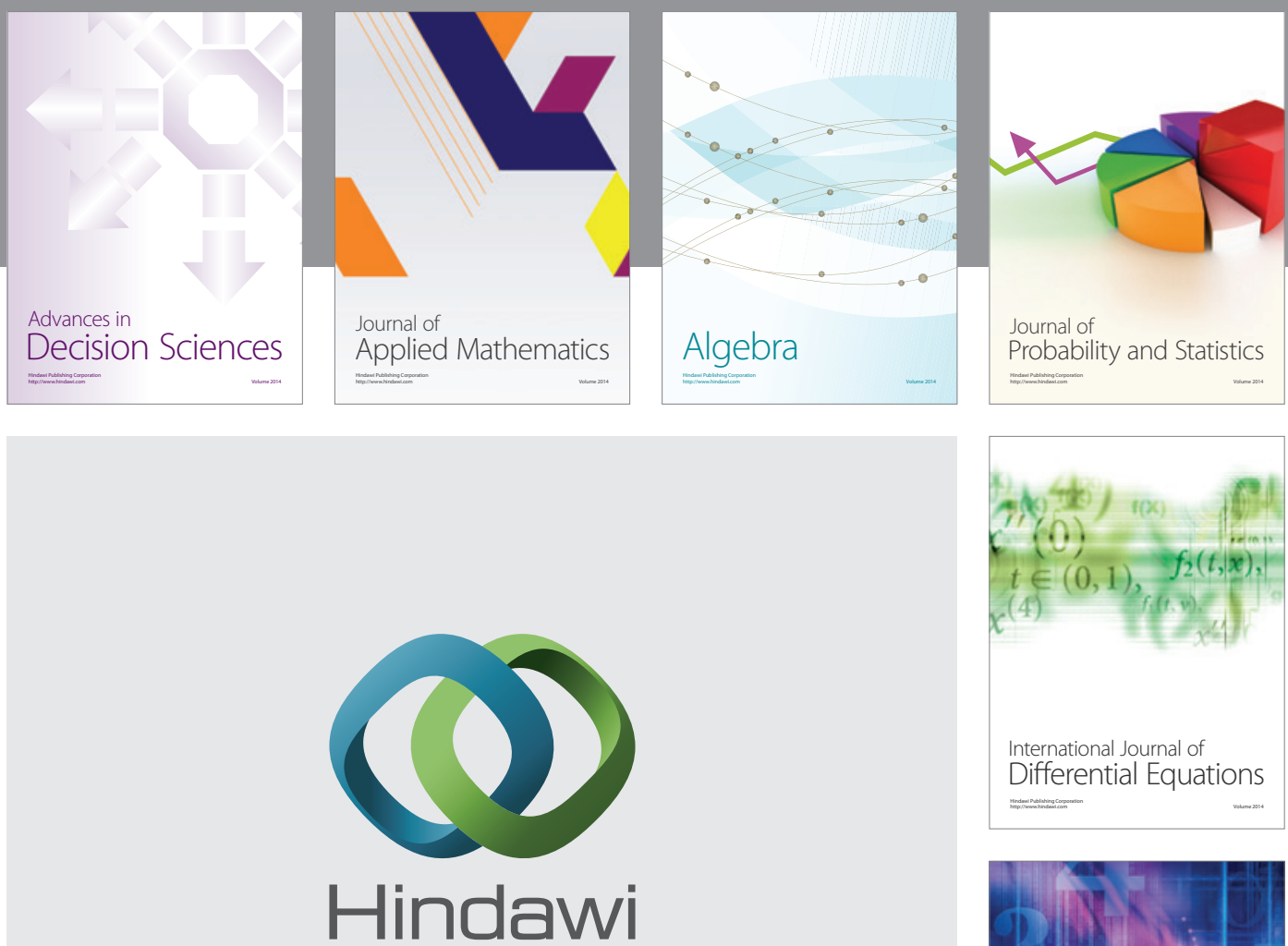

Submit your manuscripts at http://www.hindawi.com
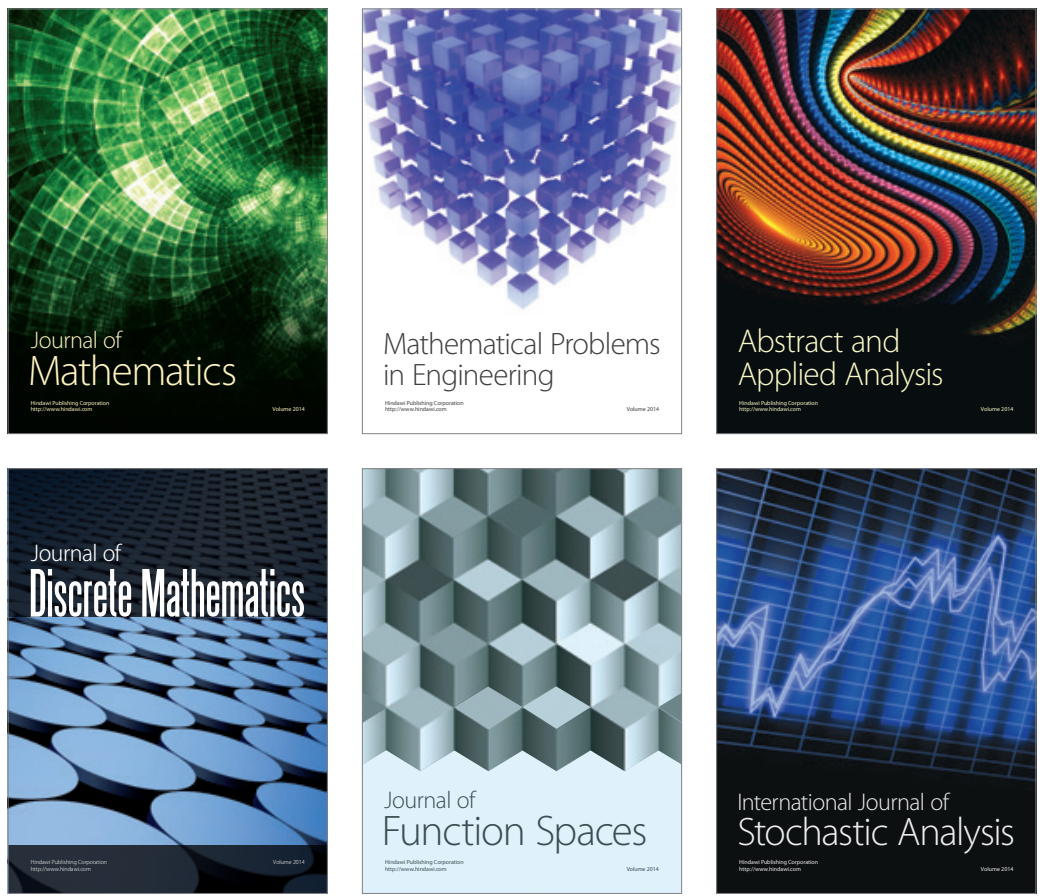

Journal of

Function Spaces

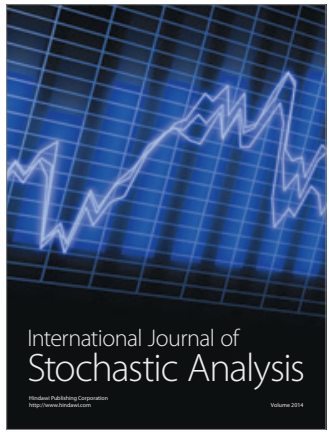

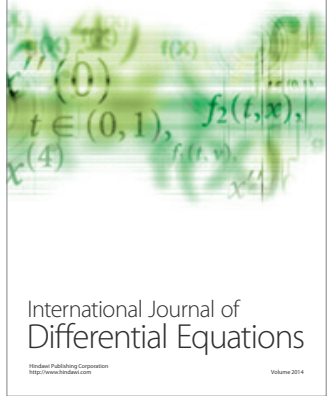
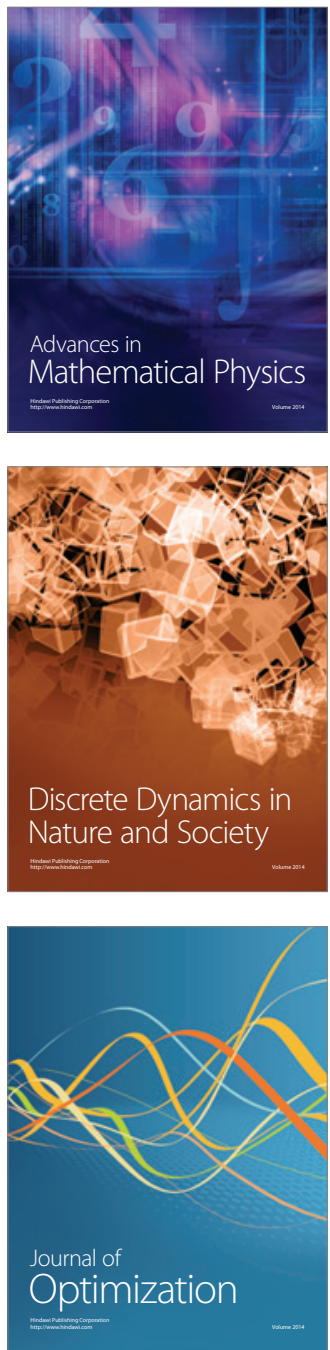